\title{
Dynamics of Imitation versus Innovation in Technological Leadership Change: Latecomers' Catch-up Strategies in Diverse Technological Regimes*
}

\author{
Sungyong Chang ${ }^{1}$, Hyunseob Kim² ${ }^{2}$ Jaeyong Song ${ }^{3}$, and Keun Lee ${ }^{4}$ \\ ${ }^{1}$ London Business School, schang@london.edu \\ ${ }^{2}$ College of Business, Jackson State University, hyunseob.kim@jsums.edu \\ ${ }^{3}$ Graduate School of Business, Seoul National University, jsong@snu.ac.kr \\ ${ }^{4}$ School of Economics, Seoul National University, kenneth@snu.ac.kr
}

June 21, 2021

\begin{abstract}
We examine the role of latecomers' optimal resource allocation between innovation and imitation in latecomers' catch-up under diverse technological regimes. Building on Nelson and Winter (1982), we develop computational models of technological leadership change. The results suggest that one-sided dependency upon either imitation or innovation deters technological leadership change. At an early stage with low-level technologies, latecomers should focus on imitation; then, as the technological gap decreases, they should allocate more $\mathrm{R} \& \mathrm{D}$ resource to innovation. We also examine the role of several variables, such as appropriability, cumulativeness, and cycle time of technologies (CTT), as related to technological regimes. The simulation results show that while low appropriability tends to increase the probability of technological leadership change, it makes imitation a more effective strategy compared to innovation; in addition, while a higher level of cumulativeness tends to reduce the probability of leadership change, it makes imitation a more valuable option because innovation becomes more difficult for latecomers. We also find an inverted U-shaped relationship between the CTT and the probability of technological leadership change. When the CTT is short, it makes sense for latecomers to allocate more resources to imitation, especially when their technology level is initially low.
\end{abstract}

Keywords: latecomers, technological leadership change, imitation, innovation, technological regime, catch-up

JEL Classification: O31, O32

*Acknowledgement: We are grateful for comments received from Jay Anand, Sendil Ethiraj, Jeho Lee, Michael Leiblein, Richard Nelson, and Oded Shenkar along with seminar participants at Columbia Business School, London Business School, Seoul National University, the Academy of Management Conference, and the Academy of International Business Conference. 


\section{Introduction}

Why some firms do better than others is one of the fundamental questions in strategy research (Nelson, 1991; Rumelt et al., 1991). Studies indicate that superior performance in some firms may persist for long periods (e.g., Caves and Porter, 1977; Lee, 2003; Lenox et al., 2006; Mueller, 1986). Much of prior work on first-mover advantage and order-of-entry effects indicates that first movers tend to perform better than latecomers for many reasons such as preemption of assets, switching costs, and complementary or specialized assets for the purpose of commercialization (e.g., Lieberman and Montgomery, 1988; Teece, 1986; Zhu and Iansiti, 2012). However, latecomers often survive and even overtake first movers in many industries (Ethiraj and Zhu, 2008; Lee and Malerba, 2017; Mitchell 1991). Recently, numerous firms from emerging economies have grown and surpassed industry leaders. Most of them were late to enter their target industries and were initially far behind the industry leaders in terms of technological capabilities (Li and Kozhikode, 2008; Mathews, 2006; Miao et al., 2021). However, they all overcame latecomer disadvantages and overtook incumbents, improving their technological capabilities beyond those of their rivals. This is known as technological catch-up. In this study, technological catch-up means that the gap between incumbents and latecomers decreases (Lee and Malerba, 2017), and technological leadership change means that a latecomer's technological capability surpasses that of industry incumbents.

Although latecomers' technology learning strategies may be heterogeneous at the firm level (Kim, 1997; Song et al., 2003), relatively little attention has been devoted to the question of how this heterogeneity, in particular, the relative weight between imitation versus innovation strategies, affects the technological catch-up process and leadership change, nor has the interaction of this heterogeneity with technological regimes been adequately studied. Latecomers' R\&D activities may be based on imitation or innovation (Nelson and Winter, 1982; Kim, 1997). In this paper, we focus on the effects of relative allocation of $R \& D$ resource between imitation and innovation in latercomer firms on technological catch-up and leadership change.

At the early stages after market entry, imitation plays a pivotal role in latecomers' learning. 
By imitating the knowledge of industry leaders, latecomers can preserve financial resources and avoid the risk of failure that comes with technological innovation (Lieberman and Montgomery, 1988; Mitchell, 1991). Imitation also allows latecomers to build technological capabilities for future innovation (Cohen and Levinthal, 1990). Imitation can also be a stepping stone to innovation, because innovation often comes from borrowing rather than invention, and new knowledge is not created on its own, but always arises from existing knowledge (Henderson and Clark, 1990; March and Simon, 1958).

However, simply pursuing an imitation strategy may not necessarily lead to technological leadership change because technological leaders keep moving on with subsequent innovations (Freeman, 1988; Jiang et al., 2011; Nelson and Winter, 1982). In other words, by the time latecomers imitate and assimilate the technologies of industry leaders, the latter has reached a higher level with new technologies (either by creating new dominant designs or by entering emerging fields); in many cases, this gap will never be closed. Thus, technological leadership change may be considered as chasing a moving target. Surpassing incumbents therefore requires an innovative method to "run faster than your target". For example, in the DRAM industry, incumbents move forward by introducing new DRAM chips with more sophisticated, next-generation technology, making it difficult for new entrants to catch up. Clearly, for latecomers to overtake incumbents, strategic decision-making is necessary as to when latecomers should shift their focus from imitation to innovation (Alchian, 1950).

Latecomers in East Asia that succeeded in catch-up and eventually gained industry leadership made timely and wise transitions from imitating leading firms' technology to innovating on their own (Kim, 1997). For example, Samsung Electronics of South Korea succeeded in doing exactly this. Table 1 shows that Samsung produced $64 \mathrm{~K}, 256 \mathrm{~K}$, and $1 \mathrm{M}$ DRAM chips based on incumbents' technologies (i.e., imitation); initially, the gap between Samsung and industry incumbents was about 25 years. In the early 1980s, Samsung increased its technological capabilities by replication and production of these chips. Then, they developed 4M and 16M DRAM chips based on their own technologies (i.e., innovation) in the late 1980s. This helped reduce the technology gap between Samsung and industry incumbents (Sohn et al., 2001). 
Finally, Samsung became the technology leader in the 1990s.

$<$ Insert Table 1 about here $>$

However, existing case studies and research regarding firms from emerging economies in which the strategy was changed from imitation to innovation do not provide an effective theoretical account of this shift, which involves multiple diverse factors at the firm, sectoral, and national levels. To examine this phenomenon, we develop a simulation model based on the technology learning and evolutionary economics of Nelson and Winter (1982) and Nelson et al. (2018). Simulation analysis is becoming increasingly popular for exploring various aspects of catching up by latecomers. Simulation-based studies have focused on different factors such as public policies (Dosi et al., 2020; Landini and Malerba, 2017), country-of-origin bias (Diodato et al., 2018), market segmentations and the roles of foreign MNCs (Li et al., 2019), organizational forms (Kim and Lee, 2003), lock-in behavior by incumbents and radical vs. adaptive innovation (Landini et al., 2017), demand-side shocks and patterns (specifically, demand-led catch-up in green industries; Landini et al., 2020), and the interaction between market regimes and catch-up strategies (Lee et al., 2017).

First, the simulation results show that dynamically shifting and balanced allocation of R\&D resources between innovation and imitation is associated with a higher possibility of technological leadership change than a lopsided allocation to either innovation or imitation. Therefore, we conclude that the chances for technological leadership change within an industry are low when firms from emerging economies either rely excessively on imitation while ignoring innovation, or focus on self-exploring innovation without learning by imitation. Also, the relative effectiveness of the innovation strategy increases as the technological gap between incumbents and latecomers narrows, suggesting that the latter should eventually increase investment in innovation as part of a dynamic technological catch-up process in order to effect leadership change.

There are also differences in the balance between innovation and imitation in diverse technological regimes. Scholars have taken the perspective that patterns of industrial innovation and evolution depend on the technological regime (Breschi et al., 2000; Tushman and Anderson, 
1986). Technological regimes differ substantially across sectors, and the relative cost and

effectiveness of innovation and imitation may vary across related variables such as appropriability, cumulativeness, and cycle time of technologies (CTT) (Audretsch, 1991; Mansfield et al., 1981; Park and Lee, 2006). The simulation results in our study show while low appropriability tends to increase the probability of technological leadership change, it also makes imitation a more effective strategy compared to innovation. We also find that while a higher level of cumulativeness tends to reduce the probability of industry leadership change, it also makes imitation a more valuable option because innovation becomes more difficult for latecomers.

This paper particularly focuses on the double-edged nature of the short CTT for latecomers. Short CTT can be either a window of opportunity, associated with quick obsolescence of existing technologies and thus low entry barriers, or a further source of difficulty, associated with the truncation of learning from existing technologies (Lall, 2000). The simulation results show an inverted U-shaped relationship between the CTT and the probability of technological leadership change such that at a certain level of CTT, the probability of leadership change is at its highest. Further simulations considering the initial technology level of the latecomer relative to that of the incumbent show that when the CTT is short and the disruption of technology is frequent, it makes more sense for latecomers to allocate more resources to imitation, especially when their initial technology level is low. By contrast, when the initial technology level of latecomers is relatively high (e.g., $\geq 60 \%$ of that of incumbents), the technological risk associated with the short CTT may have minimal effect on the optimal balance between imitation and innovation.

The remainder of this paper is organized as follows. First, we review the extant literature on the roles of imitation and innovation in technological learning and the impact of the technological regime on $R \& D$. Second, we build a model of technological learning and catch-up in diverse technological regimes based on the Schumpeterian competition model of Nelson and Winter (1982). Finally, we discuss the implications of our findings for academics and practitioners. 


\section{Literature Review}

\subsection{Imitation, Technological Catch-up, and Technological Leadership Change}

Many researchers have examined problems related to technological catch-up and technological leadership change. Newly entering latecomers are mostly at a disadvantage because they are not in a position to develop their own technology, or the technology they develop is inferior to that of industry incumbents (Gerschenkron, 1962; Lieberman and Montgomery, 1988; Mathews, 2002). For such firms, imitation can decrease the risk of failure involved with technological innovation because the technological uncertainty inherent in the process is substantially decreased if firms rely on the prior successes of incumbents (Ethiraj and Zhu, 2008; Lake, 1979; Mansfield, 1988). Furthermore, imitation can prevent the squandering of resources for latecomers, saving money and time by allowing them to develop products in-house (Mansfield et al., 1981). In fact, imitation of advanced technology may be an indispensable part of latecomers' catching up with incumbents. Indeed, many latecomers in the automobile, electronics, semiconductor, and shipbuilding industries caught up successfully by imitating the advanced technologies of industry incumbents (e.g., Kim, 1997; Lee and Lim, 2001; Sohn et al., 2009).

Such imitation is also crucial because it creates a foundation for innovation. According to the argument that innovation comes from borrowing rather than invention, new knowledge is not created on its own, but arises from understanding and learning from existing knowledge (Kim, 1997; March and Simon, 1958). Accordingly, through diverse access modes, latecomers use imitative learning to acquire technologies held by incumbents. Many latecomers assimilate technology directly through licensing, reverse engineering, or original equipment manufacturing (OEM). Also, they often acquire new technology through partnerships such as strategic alliances or joint ventures (Almeida, 1996; Mowery et al., 1996; Shan and Song, 1997; Zander and Kogut, 1995). Imitation is also accomplished by employing renowned engineers from leading firms and locating subsidiaries near such firms in order to benefit from any potential knowledge spillover (Chung and Song, 2004; Song et al., 2003; Wang, 2015; Zander and Kogut, 1995). Over time, as firms improve their technological capabilities, they can use knowledge gained from imitation to 
inform their own creative processes and engage in innovation.

Imitation has long been regarded as an easy way of assimilating incumbents' technological capability; therefore, the cost of imitation has been assumed to be little or nothing (Arrow, 1962; Nelson, 1959). In the first-generation evolutionary model of economics, imitation was considered as a costless process, and R\&D investment was assumed to be mainly related to innovation (Nelson and Winter, 1978; Nelson and Winter, 1982; Winter, 1984). In reality, imitation of technology, which entails replicating technologies viable in a different firm, is often a difficult, costly, and time-consuming process (Hatch and Mowery, 1998; Kogut and Zander, 1992; Salomon and Martin, 2008). More recent models consider the cost of imitation in various ways depending on industry characteristics (Kim and Lee, 2003; Malerba et al., 1999; Malerba and Orsenigo, 2002). To analyze the impact of R\&D investment in imitation on technological catch-up, we build a technology learning model for latecomers that explicitly presents imitation as an alternative to innovation activities, factoring in the costs of both.

\subsection{Allocating Resources between Imitation and Innovation for Technological Lead- ership Change}

The more fundamental and long-term objective of imitation is to build technological capabilities as an important base for future innovation. Incumbents keep moving by developing more advanced technology, forcing latecomers to aim at "moving targets" (i.e., not static ones) as technological leaders continue to innovate (Freeman, 1988; Malecki, 1997). By the time latecomers assimilate the imported technology, industry leaders may have already proceeded on to a higher level; therefore, engaging in imitation without innovation cannot lead to successful technological catch-up and leadership change. As observed in the case of Intel, the leading manufacturer of microprocessor chips, a positive feedback between R\&D investment and successful innovation enables incumbents to continue accumulating technological capabilities by utilizing their abundant resources.

Since both imitation and innovation are important means of competition (Nelson and Winter, 1982; Schumpeter, 1934), strategic choices may differ regarding the allocation of resources to 
these two options, and divergent competitive outcomes may result. When latecomers have especially limited resources, allocation decision-making (i.e., to innovation or imitation) may be an important strategic issue. Although imitation in the early stage is crucial for latecomers to catch up with leading companies, as noted above, the strategic decision of when to move away from imitative behavior is very important to latecomers (Alchian, 1950). In other words, the decision as to when and how resources should be allocated to either imitation or innovation is a

dynamic one. Kim (1997) suggests that Korean latecomers shifted their focus from imitation to innovation in the dynamic process of catch-up and technological leadership change. Analyzing the cases of the Korean semiconductor and electronics industries, he found that Korean firms became leaders in many industries as they dynamically changed their R\&D investment strategy from imitation to innovation. He argued that this so-called "imitation to innovation" pattern was an effective way to catch up and overtake industry leaders. To provide more systematic and rigorous insights into this important phenomenon, in this study, we examine the dynamic aspects and relative effectiveness of imitation vs. innovation and optimal resource allocation using a computer simulation based on the evolutionary economics model.

\subsection{Technological Regime and Leadership Change}

A technological regime contains economic factors that govern the trajectory of technological advancement and innovation. Differences in technological regime explain how patterns of innovation and technological evolution differ by industry (Malerba and Orsenigo, 1997; Tushman and Anderson, 1986). The notion of technological regime was first introduced in Nelson and Winter (1982)'s evolutionary theory on technological change. They distinguished two kinds of technological regime: science-based and cumulative. Since then, many researchers have explored the impact of technological regimes on technological change (Dosi, 1982), market structure (Audretsch, 1995; Cohen and Levin, 1989), new-firm survival (Audretsch, 1991), and patterns of innovation (Breschi et al., 2000; Malerba and Orsenigo, 1996). Recent studies further examined the impact of technological regime on latecomers' technological catch-up (Landini and Malerba, 2017; Lee and Lim, 2001; Li et al., 2019; Park and Lee, 2006). 
Among the various factors in a technological regime, prior research has highlighted the roles of appropriability (e.g., Breschi et al., 2000; Kogut and Zander, 1992; Nelson and Winter, 1978), cumulativeness (e.g., Nelson and Winter, 1978; Winter, 1984), and CTT (e.g., de Rassenfosse and Jaffe, 2018; Park and Lee, 2006; Lee, 2013) in competition between incumbents and latecomers. Following this research tradition and using simulation analysis, we explore the effects of appropriability, cumulativeness, and CTT on technological catch-up and leadership change. These three technological regime variables affect the effectiveness of different R\&D strategies (i.e., imitation R\&D or innovation R\&D) and, by extension, firms' competitive positions.

\subsubsection{Appropriability}

Appropriability affects imitation and R\&D activity. Appropriability has been defined as the capacity of a firm to retain the added value it creates for its own benefit. Innovation and profits from innovative activities can be protected from imitation by rival firms (e.g., Breschi et al., 2000). Protection of intellectual property rights (Mansfield et al., 1981), tacitness of knowledge

(Kogut and Zander, 1992), strategic complexity (Rivkin, 2000), and interdependency between the technology and the organization (Ethiraj and Levinthal, 2004) increases appropriability. High appropriability may increase the possibility for incumbents to monopolize their outcomes, while lowering the possibility of other firms' benefitting from these outcomes (Levin and Reiss, 1988). Under low appropriability, incumbents' outcomes can enhance utility for other firms, increasing network externality and the possibility of imitation (Levin et al., 1985).

\subsubsection{Cumulativeness}

Cumulativeness refers to the degree to which today's knowledge and innovative activities form the building blocks of tomorrow's innovation (Breschi et al., 2000). Cumulativeness also affects innovation in R\&D activities. Under conditions of high cumulativeness, today's innovators are more likely to innovate in the future by following existing trajectories. When cumulativeness is high, therefore, the economic regime may facilitate increasing returns from technological development. Under such conditions, latecomers with insufficient technological capabilities are less 
likely to innovate successfully (Park and Lee, 2006). Under low cumulativeness, on the other hand, past technological competency is less likely to affect subsequent innovation because development will not occur along the same or similar technological trajectory (Winter, 1984).

\subsection{3. $C T T$}

The cycle time of technologies (CTT) refers to how fast the value of commercial and technological knowledge decreases over time (e.g., de Rassenfosse and Jaffe, 2018; Park and Lee, 2006). De Rassenfosse and Jaffe emphasize the importance of CTT as follows: "The rate of depreciation of technology in different industries and different countries serves also as an indicator of the rate of advance of technology in those different contexts (...) it is also central to the understanding of industry dynamics" (2018: 626). Some prior works are related to the role of CTT in technological leadership change (e.g., Bosworth, 1978; Landini et al., 2017; Pakes and Schankerman, 1984). However, these studies have produced conflicting predictions of the impact of the CTT on technological leadership change because of its dual role in competitive dynamics between incumbents and latecomers. On the one hand, a short CTT (i.e., rapid knowledge obsolescence) tends to be a threat to incumbents and thus an opportunity for latecomers (e.g., Park and Lee, 2006; Suarez and Lanzolla, 2007). Park and Lee argue that "If the life expectancy of knowledge is long, mastering knowledge and technology in that field require more time. (...) the disadvantages for the latecomer might not be that big" (2006: 726). Previous empirical studies show the increased probability of technological leadership change by latecomers under short CTT regimes (e.g., Niosi and Reid, 2007; Petralia et al., 2017).

On the other hand, another body of research has emphasized the possibility that short CTT could interrupt latecomers' learning and thus be an additional barrier to latecomers (e.g., Lall, 2000; Lee, 2013). Given that building up a certain level of technological foundation is critical for innovation, rapid obsolescence of knowledge (short CTT) deters latecomers from building such a foundation because they must switch from learning existing technologies to learning new and different types of technologies, probably within a short time (Lall, 2000).

One of the contributions of this study is to reconcile these conflicting views and mixed 
empirical results. Considering the dynamic nature of the relationship between the CTT and the effectiveness of the imitation-to-innovation strategy, it is even more challenging to explore this topic without a precise theoretical model. A computational model based on Nelson and Winter's Schumpeterian competition could help us gain a deeper understanding of this topic. With such a model, we systematically examine which effect (i.e., a window of opportunity or an additional barrier) is stronger and how it dynamically shapes latecomers' optimal resource allocation strategy.

\section{Model}

\subsection{Investment Behavior and Technological Leadership Change}

\subsubsection{Technology level, RED resource allocation, and CTT}

We develop a computational model based on latecomers' imitation and innovation. The first variable in the model is the technological capability of firm $i$ at time $t, T_{i t}$. A latecomer's technological capability at time $t$ is $T_{L t}$, and an incumbent's technological capability is $T_{F t}$. The size of the physical capital stock of firm $i$ at time $t$ is $K_{i t}$. The latecomer's physical capital stock at time $t$ is $K_{L t}$, and the incumbent's physical capital stock is $K_{F t}$. In our study, if a latecomer's technological capability exceeds that of the incumbent (i.e., the latecomer becomes an industry leader) during 120 periods, it is considered that technological leadership change has occurred. We assume that an incumbent and a latecomer compete in the market.

Following Nelson and Winter's model $(1978,1982)$, we assume that the R\&D expenditure $\left(r_{i} \cdot K_{i t}\right)$ of an individual firm is proportional to that individual firm's physical capital stock, and that $r_{i}$ is identical across firms. Firms invest their R\&D resource in two types of R\&D activities: (1) R\&D for innovation and (2) R\&D for imitation. Both the incumbent and the latecomer decide

how much of their $\mathrm{R} \& \mathrm{D}$ resource to allocate between innovation and imitation. The proportion of $\mathrm{R} \& \mathrm{D}$ resource allocated to innovation is $p_{i}$. Thus, the proportion of $\mathrm{R} \& \mathrm{D}$ resource allocated to imitation is $1-p_{i}$. We assume that the incumbent has no target to imitate and allocates all resources to innovation, resulting in $p_{F}=1$. In our simulation, we examine the impact of this 
$R \& D$ resource allocation decision on the probability of technological leadership change by changing the value of $p_{i}$.

The technological capabilities of the latecomer and incumbent are determined as follows.

$$
T_{i t+1}= \begin{cases}(1-\eta) T_{L t}+t m_{L t}+t n_{L t} & \text { if } \quad i=L \\ (1-\eta) T_{F t}+t n_{F t} & \text { if } \quad i=F\end{cases}
$$

where $T_{L t}$ is the late technological capability in the current period, $\eta$ is the technological knowledge depreciation rate (i.e., we measure the CTT as $1-\eta), t m_{L t}$ is the newly gained technological capability from imitation in the prior period, and $t n_{L t}$ is the newly gained technological capability from innovation in the prior period. The CTT variable, $1-\eta$, takes a value between 0.97 and 1.0. Under a short CTT, where $1-\eta=0.97$, each firm's technological capability decreases quickly, while under a long CTT, where $1-\eta=1$, no firms lose their technological capability through technological knowledge depreciation. For the incumbent, which is committed to innovation with no imitation, technological capability is the sum of its technological capability in the current period $\left(T_{F t}\right)$, which is depreciated by $\eta$ at each time step, and newly gained technological capability from innovation in the current period $\left(\operatorname{tn}_{F t}\right)$.

\subsubsection{Imitation and appropriability}

Success in imitation R\&D follows the Bernoulli distribution with a success probability of $\kappa$. The success probability in imitation, $P\left[\theta_{i t}^{m}=1\right]$, is also proportional to the amount of R\&D resource allocated to imitation, $1-p_{i}$, since $\mathrm{R} \& \mathrm{D}$ resource should be allocated to innovation as well. Thus, the average success probability in imitation is $\left(1-p_{i}\right) \cdot \kappa$. For example, the probability of success in imitation equals $\kappa$ if all resources are allocated to imitation, whereas the probability halves to $(0.5 \cdot \kappa)$ if only half of the $\mathrm{R} \& \mathrm{D}$ resources are allocated to imitation.

$$
P\left[\theta_{i t}^{m}=1\right]=\left(1-p_{L}\right) \cdot \kappa
$$

In addition, technological capability acquired by imitation is proportional to the technological gap between the incumbent and the latecomer, like existing technological capability. In the early 
stage of catch-up, a wide technological gap suggests an abundance of acquirable technology, which decreases as the technological gap narrows. Then, the technological capability acquired by imitation is proportional to the latecomer's technological capability. If the technological capability of the latecomer is highly inferior to that of the incumbent, it is more difficult to narrow the huge technological gap between the two firms.

Appropriability, $\alpha$, refers to the degree to which an innovator can protect its innovation outcomes from imitation and secure its economic returns. The range of $\alpha$ is from 0 to 1 . The level of technology that the latecomer can accomplish through imitation is $(1-\alpha) \cdot T_{F t}$. Under no appropriability, where $\alpha=0$, the latecomer can imitate the incumbent's technology perfectly in the long run, while under $\alpha=1$, the incumbent's technology cannot be acquired by the latecomer's efforts toward imitation. Finally, if a latecomer's technological capability exceeds $(1-\alpha) \cdot T_{F t}$, the latecomer cannot increase its technological capability via imitation. Thus, the increase in technological capability via imitation is determined as follows.

$$
t m_{L t}= \begin{cases}0 & \text { if } \theta_{L t}^{m}=0 \\ \max \left[0, T_{L t}\left(1-\frac{T_{L t}}{(1-\alpha) T_{F t}}\right)\right] & \text { if } \theta_{L t}^{m}=1\end{cases}
$$

\subsubsection{Innovation and cumulativeness}

The proportion of $\mathrm{R} \& \mathrm{D}$ resource allocated to innovation, $p_{i}$, affects the probability of successful innovation, $P\left[\theta_{i t}^{n}=1\right]$, where the parameter $\theta_{i t}^{n}$ indicates whether firm $i$ succeeds in innovation $\mathrm{R} \& \mathrm{D}$ at time $t$; if firm $i$ 's innovation $\mathrm{R} \& \mathrm{D}$ is successful at time $t, \theta_{i t}^{n}$ is 1 , and otherwise $\theta_{i t}^{n}$ is 0 . The success probability of innovation $\mathrm{R} \& \mathrm{D}$ is also proportional to the amount of $\mathrm{R} \& \mathrm{D}$ investment, $R D_{i t}$. The probability of success in innovation is also proportional to the amount of $\mathrm{R} \& \mathrm{D}$ resource allocated to innovation $p_{i}$, since $\mathrm{R} \& \mathrm{D}$ resource should be allocated to imitation as well.

In addition, the probability of success of a firm's innovation is proportional to its technological capability, $T_{i t}$. The probability of successful innovation is also affected by cumulativeness, $\beta$,

which is included in our model as an exponent of the technological capability variable, $T_{i t}^{\beta}$ (Knott 
et al., 2003). Cumulativeness $\beta$ takes a value between 0 and infinity. Under no cumulativeness, where $\beta$ is equal to $0, T_{i t}^{\beta}$ is equal to 1 , and no firms have a technological disadvantage relative to the incumbent. On the other hand, as $\beta$ increases, the difference between $\bar{T}_{i t}^{\beta}\left(\bar{T}_{i t}=\max \left[T_{i t}\right)\right]$ and $T_{i t}^{\beta}$ increases. Thus, as cumulativeness increases, firms with greater technological capabilities are more likely to succeed in innovation $R \& D$ than others. The probability of successful innovation $P\left[\theta_{i t}^{n}=1\right]$ of the latecomer and incumbent is determined as follows:

$$
\operatorname{Pr}\left[\theta_{i t}^{n}=1\right]=\gamma \cdot p_{i} \cdot R D_{i t} \cdot T_{i t}^{\beta}
$$

where $\gamma$ is a positive constant, $p_{i}$ is the proportion of $\mathrm{R} \& \mathrm{D}$ resource allocated to innovation, $R D_{i t}\left(=r_{i} \cdot K_{i t}\right)$ is the amount of $\mathrm{R} \& \mathrm{D}$ investment, $T_{i t}$ is firm $i$ 's technological capability, and $\beta$ is cumulativeness.

The increase in technological capability through innovation-relative $R \& D$ activity is assumed to follow a log-normal distribution to reflect the reality that impactful innovation rarely takes place. Therefore, the function of increasing technological capability through innovation is as follows.

$$
t n_{i t}=\left\{\begin{array}{lll}
0 & \text { if } & \theta_{i t}^{n}=0 \\
\rho_{i t} & \text { if } & \theta_{i t}^{n}=1
\end{array}\right.
$$

where $\rho_{i t}$ follows the lognormal distribution with mean $\mu$ and variance $\sigma^{2}$.

\subsection{Firms' Production and Investment Behavior}

\subsubsection{Firm state variables in market dynamics}

The model for market dynamics used in this study, where firms earn profit and make investment decisions, was borrowed from Nelson and Winter $(1978,1982)$ and resembles other recent history-friendly models (Kim and Lee, 2003). The basic variables, which define each firm's behavior under market competition, are the firm's technological capability, $T_{i t}$, and the size of the firm's physical capital stock, $K_{i t}$. Technological capability determines productivity, while capital stock denotes the size of the firm and its production facilities. When a firm generates positive 
returns in the market, its physical capital stock will increase in the next period. When it generates no returns or negative returns in the market, its physical capital stock will decrease. A firm is forced to exit the industry when its technology declines below a certain minimum level due to failure in technological catch-up or when its capital stock is completely depreciated, since both conditions result in lack of further production $\left(Q_{i t}=T_{i t} \cdot K_{i t}\right)$. For simplicity, the model rules out

entry over time. This adjustment does not affect the simulation results significantly when entrants are parameterized by the same attributes as the latecomer in the initial state.

\subsubsection{Firm output}

The output of a firm is proportional to its technological capability and its capital stock. The total output of the industry is defined by the sum of the incumbent's output and the latecomer's output. We assume that the total consumer demand is given as $R$, a fixed number that follows the unit-elasticity function. Then, we control for changes in the market. Thus, at time $t$, firm output, total output of the industry, and market price are determined as follows.

$$
\begin{aligned}
Q_{t} & =\Sigma_{i} Q_{i t}=\Sigma_{i}\left(T_{i t} \cdot K_{i t}\right) \\
P_{t} & =\frac{R}{Q_{t}}
\end{aligned}
$$

There are two categories of costs: variable costs and $R \& D$ costs. We assume that these three costs do not change over time and are set as the fixed proportion per unit of capital, as in Nelson and Winter (1982). The firm's profit per unit of capital, $\left(\pi_{i t}\right)$, is defined as revenue minus the variable cost per unit of capital $\left(a v c_{i}\right)$ minus expenditure on $\mathrm{R} \& \mathrm{D}$ per unit of capital $\left(r_{i}\right)$. The profit of firm $i$ at time $t, \Pi_{i t}$ is therefore determined as follows.

$$
\Pi_{i t}=\pi_{i t} \cdot K_{i t}=\left(P_{t} \cdot T_{i t}-a v c_{i}-r_{i}\right) \cdot K_{i t}
$$

\subsubsection{Investment and capital stock}

Both incumbents and latecomers adjust their output level by changing capital investment. In 
this adjustment, the markup ratio is an important determinant in the firm's decisions about capital investment. The current markup ratio $\left(m_{i t}\right)$ of each firm is determined by the total sales revenue of the product divided by the total cost of production, as in Nelson and Winter (1982).

$$
m_{i t}=\frac{P_{t} \cdot T_{i t}}{a v c_{i}+r_{i}}
$$

Under market competition, the target markup ratio increases as the market share $\left(s_{i t}\right)$ increases, resulting in a value of 1 when the market share is 0 and an infinite value when there is a monopoly (Nelson and Winter, 1978). When a firm's perceived demand elasticity is $e_{i t}$ and its market share is $s_{i t}$, the target markup ratio $\left(m_{i t}^{*}\right)$ is determined as follows (see Nelson and Winter, 1982). We assume that the perceived demand elasticity is set to the true value of the market demand elasticity, 1.

$$
m_{i t}^{*}=\frac{e_{i t}}{e_{i t}-s_{i t}}
$$

If the current markup ratio is higher than the target markup ratio, the firm is inclined to increase output. Investment will increase when the target markup ratio is low, or when the current market ratio is higher than the target markup ratio. Thus, the firm's desired investment is precisely determined by calculating the depreciation ratio per unit of capital $\left(d_{i}\right)$ and the gap between the target and current markup ratio, as follows.

$$
I_{i t}^{*}=\left(d_{i}+\frac{m_{i t}-m_{i t}^{*}}{m_{i t}}\right) \cdot K_{i t}
$$

On the other hand, actual investment is related to the total amount of resources available as well as desired investment. The target level of investment can be realized as long as firms can finance it. The firm's actual investment is limited by the amount available and its reserve fund. Therefore, actual investment $\left(I_{i t}\right)$ and physical capital stock $\left(K_{i t+1}\right)$ at time $t+1$ are determined 
as follows.

$$
\begin{aligned}
I_{i t} & =\max \left[\left[0, \min \left[I_{i t}^{*}, \pi_{i t} \cdot K_{i t}\right]\right]\right. \\
K_{i t+1} & =K_{i t}+I_{i t}
\end{aligned}
$$

\section{Results}

The model represents (1) the effect of $R \& D$ resource allocation between imitation and innovation on the probability of technological leadership change and (2) the moderating role of technological regime in the relationship between the two catch-up strategies (imitation vs. innovation) and its effect on the probability of technological leadership change. While incumbents accumulate their technological capabilities by investing resources in innovation only, latecomers from emerging economies invest in both imitation and innovation. First, we examine various combinations of innovation and imitation and their effects on technological leadership change as catch-up proceeds. Then, we also examine variations in the probability of technological leadership change with changes in the technological regime.

The results displayed in this paper are averaged over 100,000 iterations of the simulation. Each simulation was run for 120 periods for an equivalent of 30 years in the real world. If the latecomer's technological capability exceeds that of the incumbent during these 120 periods, we regard this simulation run as a case of technological leadership change. To determine the optimal proportion of $\mathrm{R} \& \mathrm{D}$ resource to allocate to innovation, we run 500 simulations of the aforementioned model (500 x 10,000 simulations) and calculate from the results the average value for optimal R\&D resource allocation between imitation and innovation. The parameter values are specified in Appendix A.

\subsection{Imitation to Innovation}

As indicated in the model, the latecomer allocates its $R \& D$ resource to both imitation and innovation. In this section, we provide results showing the effects of changes in the ratio of 
resources allocated to innovation on the probability of technological leadership change.

Figure 1, Panel A shows that the probability of leadership change is low when the latecomer allocates too small a portion of its resource to innovation under the technological regime where appropriability, cumulativeness, and the CTT are moderate $(\alpha=0.2, \beta=1.0,1-\eta=0.985)$. The probability increases as more resources are allocated to innovation, but after reaching a peak around 0.65 , the probability of leadership change decreases, thus indicating an inverted U-shaped relationship. This means that allocating $65 \%$ of $\mathrm{R} \& \mathrm{D}$ resource to innovation and $35 \%$ to imitation produces the highest probability of leadership change. This result suggests that a balanced allocation between innovation and imitation is better than a lopsided allocation to either innovation or imitation. This inverted U-shaped relationship remains robust across all the possible combinations of parameters, even after including the technological regime variables. The notable exception is the case when the gap between the incumbent and latecomer is small. This case is examined in the following analysis.

$<$ Insert Figure 1 about here $>$

As the relative technological capability of the latecomer increases, the optimal amount of resource allocated to innovation also increases, as shown in Figure 1, Panel A. As the latecomer builds its technological capabilities, the technological gap between the incumbent and the latecomer narrows. Figure 2, Panel B shows that a wide technological gap moves the optimal allocation point toward imitation because the relative advantage of investing in imitation increases. A narrow technological gap, by contrast, moves the optimal point toward innovation, increasing the relative advantage of allocating resource toward innovation. For example, when the relative technological capability of the latecomer is close to 0 , the latecomer should allocate about $60 \%$ of its $\mathrm{R} \& \mathrm{D}$ resource to innovation in order to maximize the probability of leadership change. When the relative technological capability of the latecomer is larger than 0.8 , the latecomer should allocate more than $90 \%$ of its $R \& D$ resource to innovation in order to maximize the probability of leadership change.

$<$ Insert Figure 2 about here $>$ 
The results in Figures 1 and 2 reflect the case where all technological regime variables have moderate values. The results are consistent over various technological regime conditions. We check the robustness of the results later on in the sensitivity test section.

\subsection{Appropriability}

Appropriability, the degree to which incumbents can protect their innovation outcomes from imitation, affects the probability of technological leadership change. Since appropriability hinders imitation, the higher the appropriability of the technology (represented by a higher value of $\alpha$ ), the lower the probability of technological leadership change, as shown in Figure 3, Panel A. The probability of leadership change is highest when $\alpha$ equals 0 , meaning no protection of the incumbent's innovation outcomes. Imitation turns out to be more beneficial for latecomers since all the incumbent's technologies can be imitated when $\alpha$ equals 0 . As appropriability increases, the incumbent's technologies become less imitable, which lowers the probability of technological leadership change. In the extreme case when appropriability exceeds 0.4 , the results indicate that technological leadership change rarely occurs.

Latecomers can catch up with incumbents and save resources by engaging in imitation R\&D, which is the less risky and less costly option. We identify the optimal proportion of resources allocated to imitation or innovation within a range of $\alpha$ from 0 to 0.4 since the probability of leadership change is extremely low when $\alpha$ exceeds 0.4. Figure 3, Panel B shows that balancing $R \& D$ resource between imitation and innovation is beneficial at different appropriability levels.

Finally, as the level of appropriability increases, the latecomer should allocate more resources to innovation to increase the probability of technological leadership change, as shown in Figure 3, Panel C. Imitation is relatively more effective than innovation under low appropriability, while innovation is relatively more effective under high appropriability. For example, when $\alpha$ is close to 0, a latecomer should allocate only $40 \%$ of its $R \& D$ resource to innovation in order to maximize the probability of leadership change. When $\alpha$ is larger than 0.06 , the latecomer needs to allocate more than $60 \%$ of its $R \& D$ resourcs to innovation. 


\section{$<$ Insert Figure 3 about here $>$}

\subsection{Cumulativeness}

Cumulativeness refers to the degree to which past technological capabilities affect the probability of success of the present innovation. When the technological regime is highly cumulative, innovation will be highly dependent on existing technological capabilities and building blocks. This will be beneficial for incumbents in terms of innovation R\&D since incumbents have better technological capabilities and more existing building blocks. Figure 4, Panel $\mathrm{A}$ shows that as the value for the cumulativeness variable, $\beta$, changes from 0 (low cumulativeness) to 4 (high cumulativeness), the probability of technological leadership change decreases. When cumulativeness is high, it is difficult for latecomers with lower technological capability to catch up with incumbents since innovation $R \& D$ is relatively ineffective. This result confirms that for latecomers, gaining technological leadership is more difficult when innovation is based on past technology.

In addition, Figure 4, Panel B shows that balancing R\&D resource between imitation and innovation is relatively more or less beneficial depending on the cumulativeness level. It also shows that in a highly cumulative regime $(\beta=4)$, the optimal point moves toward imitation. Since higher cumulativeness implies better technological capabilities for incumbents, technological knowledge gained from imitation becomes more valuable for latecomers. In a low cumulative

regime $(\beta=0)$, the effectiveness of innovation $\mathrm{R} \& \mathrm{D}$ is relatively higher than in a high cumulative regime; thus, the optimal point moves toward innovation. Looking at the optimal allocation of $\mathrm{R} \& \mathrm{D}$ resource in Figure 4, Panel $\mathrm{C}$, we see that when $\beta$ is close to 0 , the latecomer should allocate more than $70 \%$ of its $R \& D$ resource to innovation in order to maximize the probability of leadership change. When $\beta$ is close to 4 , the latecomer should allocate about $50 \%$ of its $\mathrm{R} \& \mathrm{D}$ resource to innovation.

$<$ Insert Figure 4 about here $>$ 


\subsection{CTT}

We now turn to the question of how the CTT affects technological leadership change and optimal imitation-innovation balance for latecomers. If the CTT is short, technological capability decreases quickly for both latecomers and incumbents.

Figure 5, Panel A shows an inverted U-shaped relationship between the CTT and the probability of technological leadership change. This pattern is based on the average of the leadership change probabilities in the cases where the amount of $\mathrm{R} \& \mathrm{D}$ resource allocated to innovation is between 0 and 1. As the CTT changes from 0.97 (short CTT) to 0.985 (moderate CTT), the probability of technological leadership change increases. The probability of leadership change reaches its peak when CTT is around 0.985. After this point, as $1-\eta$ changes from 0.985 (moderate CTT) to 1.0 (long CTT), the probability of technological leadership change decreases. These results suggest both positive and negative effects of CTT. First, a shorter CTT provides a window for latecomers to catch up and in which leadership change may occur. Second, a shorter CTT also hinders latecomers' catch-up due to truncated learning. When the CTT is longer than 0.985, the negative effect dominates, leading to a negative relationship between the CTT and catch-up probability. In contrast, when the CTT is shorter than 0.985 , the positive effect dominates. This is the rationale behind the inverted U-shaped relationship between the CTT and technological leadership change.

This inverted U-shaped relationship between the proportion of $\mathrm{R} \& \mathrm{D}$ resource allocated to innovation and the probability of leadership change is sustained across the range of CTT, as shown in Figure 5, Panels B and C. Lastly, Figure 5, Panel D summarizes this relationship between the CTT and the optimal resource allocation toward innovation $\mathrm{R} \& \mathrm{D}$. The linear line is somewhat flat, indicating the not-so-dramatic impact of the CTT variable on the relative balance between imitation and innovation.

$<$ Insert Figure 5 about here $>$

We further delve into the role of the CTT as it interacts with the latecomer's technological 
capability relative to the incumbent. Figure 6, Panel A shows the impact of the CTT on the probability of technological leadership change at different levels of technological capability of the latecomer. As the technological capability of the latecomer relative to the incumbent increases, the overall probability of technological leadership change increases, and the inverted U-shaped relationship between the CTT and the probability of technological leadership change is sustained. However, the peak probability of leadership change does not change along with changes in the latecomer's relative technological capability.

On the other hand, Figure 6, Panel B shows the impact of the CTT on the optimal R\&D resource allocation for the latecomer according to the latecomer's technological capability relative to the incumbent. The important pattern to note here is that when the technological capability of the latecomer relative to the incumbent is low under a shorter CTT, the latecomer should allocate more $R \& D$ resource to imitation to increase the probability of technological leadership change. However, there is no significant difference in the optimal allocation of $R \& D$ resource regarding the length of the CTT when the latecomer's relative technological capability exceeds $60 \%$ of that of the incumbent.

These results extend our understanding of the role of the CTT from previous literature, emphasizing the disadvantages of a shorter CTT for latecomers whose levels of technology are low (e.g., Lall, 2000; Lee, 2013). Prior work highlights the initial technological capabilities of latecomers (e.g., Zhang et al., 2021), which play an important role in the early stages of the catch-up process; therefore, latecomers should build their technological capabilities via imitation when the technological gap between them and the incumbents is wide. The importance of imitation in building technological capability for latecomers is very evident when the CTT is shorter. Under these conditions, the risk of lagging behind increases for latecomers when they lack sufficient technological capabilities. Such latecomers should focus on a dynamic imitation-to-innovation strategy to maximize the probability of technological leadership change when the CTT is shorter.

\footnotetext{
$<$ Insert Figure 6 about here $>$
} 


\subsection{Sensitivity Test}

We examine whether our findings are robust when the technological regime changes in three

ways. Table 2 shows that in various situations, the relationships between the technological regime variables and the probability of leadership change are sustained. First, as the level of appropriability increases, the probability of leadership change decreases. Second, as the level of cumulativeness increases, the probability of leadership change decreases. Third, there is an inverted U-shaped relationship between the CTT and the probability of leadership change. In addition, Table 3 shows that the "imitation to innovation" strategy is still effective when appropriability, cumulativeness, and the CTT jointly affect the catch-up process. The optimal amount of R\&D resource allocated to innovation gradually increases as the latecomer's technology level relative to the incumbent's increases in every case presented.

$<$ Insert Table 2 and Table 3 about here $>$

\section{Key Findings and Implications}

\subsection{Imitation to Innovation}

Our findings contribute to the body of research on the entry-order effect and first-mover advantage. As Ethiraj and Zhu (2008) note, relatively little attention has been devoted to the question of how latecomers overcome the first-mover advantage of incumbents. From a latecomer's point of view, we examine the effect of strategies for allocation of $R \& D$ resource on technological catch-up. The results of the simulation suggest that it is important to strike a fine and dynamic balance between imitation and innovation in order for latecomers to catch up with incumbents and realize a leadership change in a given industry. First, imitation is crucial for technological catch-up and leadership change because it creates a foundation for innovation (Kim, 1997) and prevents the squandering of latecomers' resources (Mansfield et al., 1981). Excessive innovation with no imitation can never provide latecomers with technological capabilities to embark on catch-up. Second, innovation is also crucial for catch-up and leadership change since latecomers 
must aim at "moving targets" (i.e., not static ones) as technological leaders continue to innovate (Freeman, 1988; Malecki, 1997). By the time latecomers assimilate an imported technology, industry leaders will have already proceeded on to a higher level. Thus, excess imitation with no innovation also cannot lead to successful technological catch-up and leadership change.

Furthermore, the optimal amount of R\&D resource to allocate between imitation and innovation changes dynamically depending on the stage. In the initial stage of catch-up, latecomers should focus on imitation and build technological capabilities quickly. Then, in the later stages, when the technological gap has narrowed, latecomers should increase investment in innovation and attempt technological leapfrogging. This result supports the conjecture of Alchian (1950) that imitative behavior should be abandoned at the "right" time for latecomers to become successful innovators. For example, Korean firms such as Samsung Electronics and LG Electronics gained competitive advantages in the consumer electronics industry this way. In the 1970s, they pursued duplicative imitation by manufacturing standardized mature products, but moved on to creative imitation in the 1980 s by adding several additional features to relatively immature products based on their technological capabilities accumulated in the earlier duplicative imitation stage. In the 1990s, Samsung Electronics and LG Electronics actively established R\&D research centers in countries with developed economies including the U.S., Japan, and Germany, and strategically allied themselves with or acquired technologically advanced firms in these countries at the same time. Their investment in innovation seemed to pay off in the 21st century, as their technological capabilities in consumer electronics became the world's best. This case of technological catch-up and leadership change in the consumer electronics industry illustrates the effectiveness of a strategic move from imitation to innovation as catch-up proceeds.

\subsection{Technological Regime, Technological Catch-up, and Leadership Change}

To gain further insight into the effects of technological regime on technological catch-up and leadership change, we examine three major technological regime variables: appropriability, cumulativeness, and the CTT, which are closely related to imitation and innovation (Breschi et al., 2000; Knott and Posen, 2009; Park and Lee, 2006). 


\subsubsection{Appropriability}

In this study, the results of the analysis indicate that the greater the appropriability of a technology, the harder it is for the latecomer to build technological capacity through imitation, resulting in a low probability of technological leadership change. Also, imitation is relatively more effective than innovation under low appropriability, and innovation is relatively more effective under high appropriability.

Although innovation in the automobile industry is rather predictable and depends less on science than innovation in other industries (Pavitt, 1984), the industry is classified as highly appropriable. This is because tacit knowledge is crucial for maintaining high productivity in the automobile industry. This classification is supported by the diversity and interdependency of components used in the automobile manufacturing process, which hinder the formation of a global market for automobile components (Clark and Fujimoto, 1991; Lee, 2007). In the 1970s, the Korean automobile industry was in the assembling stage, focusing on localization; in the 1980s, it entered the mass production stage, focusing on exports, and in the 1990s, it entered the in-house development stage, at which $90 \%$ of the components utilized in the production process were produced in Korea. However, high appropriability preserves a considerable gap in terms of high technology, especially for next-generation automobiles including hybrid cars, fuel cell vehicles, and intelligent vehicles. In developing hybrid cars, Japanese firms such as Toyota and Honda, which had already secured numerous technologies by patenting, made it more difficult for other companies to imitate their technology. Under these conditions of high appropriability, Hyundai-Kia Motors presented the next level of competition by detouring to an innovation strategy which focuses on developing LPG hybrid cars and hydrogen fuel cell cars. This case demonstrates that innovation may count more under conditions of high appropriability.

The PC industry, on the other hand, is an example of low appropriability. In 1981, IBM first launched the open standard PC, components of which could be easily assembled and procured from the market. This open platform, the most powerful factor that led to IBM's success, transformed a technology-intensive computer industry into a labor-intensive assembly industry. The introduction of the open platform lowered appropriability. In 1982, various IBM-compatible 
PC manufacturers, such as Compaq, entered the market and promoted the industry. In Korea as

well, many manufacturers, such as Sambo Computer, recorded rapid growth in the 1980s with the global boom in the PC market (Lee and Lim, 2001). In the 1990s and 2000s, Chinese and Taiwanese manufacturers marked similar high growth with the help of cost advantages and big domestic markets. In 2013, LENOVO from China, which had acquired IBM's PC department, gained first place as a global PC manufacturer, and Acer from Taiwan also gained fourth place. These examples of technological catch-up show that imitation can be highly effective under low appropriability.

\subsubsection{Cumulativeness}

In this study, we investigate the effect of cumulativeness. The higher the level of cumulativeness, the greater the advantage for incumbents with prior technological capabilities, resulting in a lower probability of leadership change. Also, under higher cumulativeness, imitation is more valuable because incumbents' technological capabilities are more valuable.

A representative case of cumulativeness can be observed in the semiconductor industry. In the system semiconductor industry, technological discontinuities between generations have been relatively few, and small-quantity batch production is the norm, by contrast to the memory semiconductor industry, which relies on mass production (Joo, 2009). Since the design capability for small-quantity batch production is gained mainly from earlier design experiences, the technological advantage of Intel, the industry's first mover, has been sustained due to high technological cumulativeness.

Conversely, in the memory semiconductor industry, technological discontinuities between generations were more evident in the early stage (until the early 1990s) of the industry's evolution than the later stage (Kim, 1997). These technological discontinuities between generations, resulting from low cumulativeness in the technological regime, facilitated technological catch-up. Leadership positions in the memory semiconductor industry were occupied by US firms such as Intel and Texas Instruments in the 1970s, moved to Japanese firms such as Hitachi and Toshiba in the 1980s, and then to a Korean firm, Samsung Electronics, in the 1990s. 
Looking back at the success of Samsung Electronics, we note that technologically new products prepared for the next generation played an important role in this low-cumulativeness industry. Since incumbents such as Texas Instruments, Motorola, NEC, Toshiba, and Hitachi were reluctant to transfer their semiconductor technologies to Samsung Electronics (Kim, 1997), the company initiated in-house development in 1986 and developed 4MB and 16MB chips using its own technologies. After that, Samsung made headway in developing 64MB and 256MB DRAM chips, becoming the leading company in the world (Joo, 2009). The case of Samsung Electronics supports the result in our study that under low technological cumulativeness, innovation efforts targeting next-generation technology are more effective than imitation of present-generation technology.

\subsubsection{The $C T T$}

In this study, we also examine the role of the CTT, which is closely related to industry leaders' current advantages and latecomers' build-up of technological capability. Our findings suggest that there exists an inverted U-shaped relationship between the CTT and the probability of technological leadership change, which means that with certain CTTs, the probability of leadership change is highest. In other words, the non-linearity between the CTT and catch-up possibility means that when the CTT is very short, catch-up probability is low. Our findings also highlight the importance of strategically managing the two opposite effects of a short CTT: on the one hand, the obsolescence of incumbents' technological capabilities, but on the other, interrupted learning for latecomers. The simulation shows that under the regime of a short CTT, it makes more sense for latecomers to allocate more resources to imitation, especially when the initial technology level of the latecomers is low. By contrast, when the initial technology level of

the latecomers is relatively high, the length of the CTT does not much affect the optimal balance of resources between imitation and innovation.

One might think that in sectors with short CTTs, latecomers should adopt an innovation-based catch-up strategy. However, our simulation results indicate that it depends upon their initial level of technology. If that level is low, then latecomers should devote more resources 
to imitation than otherwise. This is consistent with the experience of Korean catch-up in IT industries, which is an example of a short CTT-based sector. While Samsung has achieved remarkable catch-up in this short CTT-based sector, it initially relied on imitation when its technology level was low, as evidenced by its heavy citation of Sony's patents in the early days and in the 1980s (Joo and Lee, 2010). However, over time (toward the end of the 1990s), Samsung had reduced its reliance on Sony as a source of knowledge.

\section{Contributions and Limitations}

This study is one of the first theory-based attempts to investigate how decisions of latecomers regarding strategic $R \& D$ resource allocation can affect the probability of technological leadership change in diverse technological regimes. On the one hand, our computational model provides a good complement to previous case studies and empirical findings in the literature. On the other hand, while prior researchers had difficulties identifying the individual effects of appropriability, cumulativeness, and the CTT because these major attributes of technological regime are intertwined in an abstruse fashion, the current study, using computational simulation, separates out the effects of each technological regime variable, in particular the non-linear and double-edged nature of a short CTT. Further, when the CTT is short, our findings indicate that it makes sense for latecomers to allocate more resources to imitation, especially when their initial technology level is low. Our findings also show that while low appropriability tends to increase the probability of technological leadership change, it makes imitation a more effective strategy, and that while a higher level of cumulativeness tends to reduce the probability of leadership change, it makes imitation a more valuable option because innovation becomes more difficult for latecomers.

Our work also has some limitations. Our model does not include the strategic behaviors of the incumbent. In this paper, this simplifying assumption allows us to focus on the main effect of R\&D resource allocation for latecomers on the probability of technological leadership change. As has been frequently noted, incumbents in reality will strive to prevent technological catch-up by latecomers by registering patents or aggressively investing in R\&D and facilities (Caves and 
Porter, 1977; Rothaermel and Thursby, 2007). This assumption may be relaxed in future work. Also, it would be particularly interesting from our perspective to clarify the different strategic behaviors of incumbents in their efforts to prevent technological leadership change. 


\section{REFERENCES}

Alchian, A. A. (1950), 'Uncertainty, evolution, and economic theory', The Journal of Political Economy 58(3), 211-221.

Almeida, P. (1996), 'Knowledge sourcing by foreign multinationals: patent citation analysis in the US semiconductor industry', Strategic Management Journal 17(S2), 155-165.

Arrow, K. J. (1962), Economic Welfare and the Allocation of Resources for Invention, in 'Readings in Industrial Economics', pp. 609-626.

Audretsch, D. B. (1991), 'New-firm survival and the technological regime', The Review of Economics and Statistics pp. 441-450.

Audretsch, D. B. (1995), 'Innovation, growth and survivel', International Journal of Industrial Organization 13(4), 441-457.

Bosworth, D. L. (1978), 'The Rate of Obsolescence of Technical Knowledge-A Note', The Journal of Industrial Economics pp. 273-279.

Breschi, S., Malerba, F. and Orsenigo, L. (2000), 'Technological regimes and Schumpeterian patterns of innovation', The Economic Journal 110(463), 388-410.

Caves, R. E. and Porter, M. E. (1977), 'From entry barriers to mobility barriers: Conjectural decisions and contrived deterrence to new competition', The Quarterly Journal of Economics pp. 241-261.

Chung, W. and Song, J. (2004), 'Sequential investment, firm motives, and agglomeration of Japanese electronics firms in the United States', Journal of Economics Management Strategy 13(3), 539-560.

Clark, K. B. and Fujimoto, T. (1991), Product development performance: Strategy, organization, and management in the world auto industry, Harvard Business Press, Cambridge, MA.

Cohen, W. M. and Levinthal, D. A. (1989), 'Innovation and learning: the two faces of R D', The Economic Journal 99(397), 569-596.

Cohen, W. M. and Levinthal, D. A. (1990), 'Absorptive capacity: a new perspective on learning and innovation', Administrative Science Quarterly 35(1), 128-152.

de Rassenfosse, G. and Jaffe, A. B. (2018), 'Econometric evidence on the depreciation of innovations', European Economic Review 101, 625-642.

Diodato, D., Malerba, F. and Morrison, A. (2018), 'The made-in effect and leapfrogging: A model of leadership change for products with country-of-origin bias', European Economic Review 101, 297-329.

Dosi, G. (1982), 'Technological paradigms and technological trajectories', Research Policy $\mathbf{1 1}(3), 147-162$.

Dosi, G., Roventini, A. and Russo, E. (2020), 'Public policies and the art of catching up: matching the historical evidence with a multicountry agent-based model', Industrial and Corporate Change .

Ethiraj, S. K. and Levinthal, D. A. (2004), 'Modularity and Innovation in Complex Systems', Management Science 50(2), 159-173.

Ethiraj, S. K. and Zhu, D. H. (2008), 'Performance effects of imitative entry', Strategic Management Journal 29(8), 797-817. 
Freeman, C. (1988), Technology gaps, international trade and the problems of smaller and less-developed economies, in C. Freeman and B. A. Lundvall, eds, 'Small countries facing the technological revolution', Pinter publishers, London, pp. 67-85.

Gerschenkron, A. (1962), Economic backwardness in historical perspective: a book of essays, Belknap Press of Harvard University Press Cambridge, MA.

Hatch, N. W. and Mowery, D. C. (1998), 'Process innovation and learning by doing in semiconductor manufacturing', Management Science 44(11-part-1), 1461-1477.

Henderson, R. M. and Clark, K. B. (1990), 'Architectural Innovation: The Reconfiguration of Existing Product Technologies and the Failure of Established Firms', Administrative Science Quarterly 35(1), 9-30.

Jiang, L., Tan, J. and Thursby, M. (2011), 'Incumbent firm invention in emerging fields: evidence from the semiconductor industry', Strategic Management Journal 32(1), 55-75.

Joo, D. Y. (2009), An analysis on the status of Korean semiconductor industry (in Korean), Technical report, KIET, Seoul.

Joo, S. and Lee, K. (2010), 'Samsung's catch-up with Sony: an analysis using US patent data', Journal of the Asia Pacific Economy 15(3), 271-287.

Kim, C.-W. and Lee, K. (2003), 'Innovation, technological regimes and organizational selection in industry evolution: a 'history friendly model' of the DRAM industry', Industrial and Corporate Change 12(6), 1195-1221.

Kim, L. (1997), Imitation to innovation: The dynamics of Korea's technological learning, Harvard Business Press, Cambridge, MA.

Knott, A. M., Bryce, D. J. and Posen, H. E. (2003), 'On the Strategic Accumulation of Intangible Assets', Organization Science 14(2), 192-207.

Knott, A. M. and Posen, H. E. (2009), 'Firm RD behavior and evolving technology in established industries', Organization Science 20(2), 352-367.

Kogut, B. and Zander, U. (1992), 'Knowledge of the Firm, Combinative Capabilities, and the Replication of Technology', Organization Science 3(3), 383-397.

Lake, A. W. (1979), 'Technology creation and technology transfer by multinational firms', Research in International Business and Finance 1(2), 137-177.

Lall, S. (2000), 'The Technological structure and performance of developing country manufactured exports, 1985-98', Oxford Development Studies 28(3), 337-369.

Landini, F., Lee, K. and Malerba, F. (2017), 'A history-friendly model of the successive changes in industrial leadership and the catch-up by latecomers', Research Policy 46(2), 431-446.

Landini, F., Lema, R. and Malerba, F. (2020), 'Demand-led catch-up: a history-friendly model of latecomer development in the global green economy', Industrial and Corporate Change.

Landini, F. and Malerba, F. (2017), 'Public policy and catching up by developing countries in global industries: a simulation model', Cambridge Journal of Economics 41(3), 927-960.

Lee, J. (2003), 'Innovation and strategic divergence: An empirical study of the US pharmaceutical industry from 1920 to 1960', Management Science 49(2), 143-159.

Lee, K. (2007), Economics of East Asia and Technological Catch-up (In Korean), Parkyoungsa, Seoul. 
Lee, K. (2013), Schumpeterian analysis of economic catch-up: Knowledge, path-creation, and the middle-income trap, Cambridge University Press, Cambridge, UK.

Lee, K. and Lim, C. (2001), 'Technological regimes, catching-up and leapfrogging: findings from the Korean industries', Research Policy 30(3), 459-483.

Lee, K. and Malerba, F. (2017), 'Catch-up cycles and changes in industrial leadership: Windows of opportunity and responses of firms and countries in the evolution of sectoral systems', Research Policy 46(2), 338-351.

Lee, K., Park, J. and Yoon, M. (2017), 'Industry dynamics with diversity in firms' catch-up strategies and demand conditions: a simulation approach', Economics of Innovation and New Technology 26(8), 755-778.

Lenox, M. J., Rockart, S. F. and Lewin, A. Y. (2006), 'Interdependency, competition, and the distribution of firm and industry profits', Management Science 52(5), 757-772.

Levin, R. C., Cohen, W. M. and Mowery, D. C. (1985), 'RD Appropriability, Opportunity, and Market Structure: New Evidence on Some Schumpeterian Hypotheses', The American Economic Review 75(2), 20-24.

Levin, R. C. and Reiss, P. C. (1988), 'Cost-Reducing and Demand-Creating RD with Spillovers', RAND Journal of Economics 19(4), 538-556.

Li, D., Capone, G. and Malerba, F. (2019), 'The long march to catch-up: a history-friendly model of China's mobile communications industry', Research Policy 48(3), 649-664.

Li, J. and Kozhikode, R. K. (2008), 'Knowledge management and innovation strategy: The challenge for latecomers in emerging economies', Asia Pacific Journal of Management 25(3), 429-450.

Lieberman, M. B. and Montgomery, D. B. (1988), 'First-mover advantages', Strategic Management Journal 9(S1), 41-58.

Malecki, E. J. (1997), Technology and Economic Development: The Dynamics of Local, Regional and National Competitiveness, Addison Wesley Longman, London.

Malerba, F., Nelson, R. R., Orsenigo, L. and Winter, S. G. (1999), 'History-friendly'models of industry evolution: the computer industry', Industrial and Corporate Change 8(1), 3-40.

Malerba, F. and Orsenigo, L. (1996), 'Schumpeterian patterns of innovation are technology-specific', Research Policy 25(3), 451-478.

Malerba, F. and Orsenigo, L. (1997), 'Technological regimes and sectoral patterns of innovative activities', Industrial and Corporate Change 6(1), 83-118.

Malerba, F. and Orsenigo, L. (2002), 'Innovation and market structure in the dynamics of the pharmaceutical industry and biotechnology: towards a history-friendly model', Industrial and Corporate Change 11(4), 667-703.

Mansfield, E. (1988), 'Industrial RD in Japan and the United States: A comparative study', The American Economic Review 78(2), 223-228.

Mansfield, E., Schwartz, M. and Wagner, S. (1981), 'Imitation costs and patents: an empirical study', The Economic Journal 91(364), 907-918.

March, J. G. and Simon, H. A. (1958), Organizations., Wiley, Oxford, England.

Mathews, J. A. (2002), 'Competitive Advantages of the Latecomer Firm : A Resource-Based Account of Industrial', Asia Pacific Journal of Management 19(4), 467-488. 
Mathews, J. A. (2006), 'Dragon multinationals: New players in 21st century globalization', Asia Pacific Journal of Management 23(1), 5-27.

Miao, Y., Salomon, R. M. and Song, J. (2021), 'Learning from Technologically Successful Peers: The Convergence of Asian Laggards to the Technology Frontier', Organization Science 32(1), 210-232.

Mitchell, W. (1991), 'Dual clocks: Entry order influences on incumbent and newcomer market share and survival when specialized assets retain their value', Strategic Management Journal 12(2), 85-100.

Mowery, D. C., Oxley, J. E. and Silverman, B. S. (1996), 'Strategic alliances and interfirm knowledge transfer', Strategic Management Journal 17(S2), 77-91.

Mueller, D. C. (1986), Profits in the long run, Cambridge University Press, Cambridge.

Nelson, R. R. (1959), 'The simple economics of basic scientific research', Journal of Political Economy 67(3), 297-306.

Nelson, R. R. (1991), 'Why Do Firms Differ, and How Does it Matter?', Strategic Management Journal 12, 61-74.

Nelson, R. R., Dosi, G., Helfat, C., Pyka, A., Saviotti, P. P., Lee, K., Dopfer, K., Malerba, F. and Winter, S. G. (2018), Modern Evolutionary Economics: An Overview, Cambridge University Press, Cambridge, UK.

Nelson, R. R. and Winter, S. G. (1978), 'Forces generating and limiting concentration under Schumpeterian competition', The Bell Journal of Economics pp. 524-548.

Nelson, R. R. and Winter, S. G. (1982), An evolutionary theory of economic change, Harvard University Press, Boston, MA.

Niosi, J. and Reid, S. E. (2007), 'Biotechnology and nanotechnology: science-based enabling technologies as windows of opportunity for LDCs?', World Development 35(3), 426-438.

Pakes, A. and Schankerman, M. (1984), The rate of obsolescence of patents, research gestation lags, and the private rate of return to research resources, in 'RD, patents, and productivity', University of Chicago Press, pp. 73-88.

Park, K. H. and Lee, K. (2006), 'Linking the technological regime to the technological catch-up: Analyzing Korea and Taiwan using the US patent data', Industrial and Corporate Change 15(4), 715-753.

Pavitt, K. (1984), 'Sectoral patterns of technical change: towards a taxonomy and a theory', Research Policy 13(6), 343-373.

Petralia, S., Balland, P.-A. and Morrison, A. (2017), 'Climbing the ladder of technological development', Research Policy 46(5), 956-969.

Rivkin, J. W. (2000), 'Imitation of Complex Strategies', Management Science 46(6), 824-844.

Rothaermel, F. T. and Thursby, M. (2007), 'The nanotech versus the biotech revolution: Sources of productivity in incumbent firm research', Research Policy 36(6), 832-849.

Rumelt, R. P., Schendel, D. and Teece, D. J. (1991), 'Strategic Management and Economics', Strategic Management Journal 12(S2), 5-29.

Salomon, R. and Martin, X. (2008), 'Learning, knowledge transfer, and technology implementation performance: A study of time-to-build in the global semiconductor industry', Management Science 54(7), 1266-1280. 
Schumpeter, J. A. (1934), The theory of economic development: An inquiry into profits, capital, credit, interest, and the business cycle, Harvard University Press, Cambridge, MA.

Shan, W. and Song, J. (1997), 'Foreign direct investment and the sourcing of technological advantage: evidence from the biotechnology industry', Journal of International Business Studies 28(2), 267-284.

Sohn, E., Chang, S. and Song, J. (2009), 'Technological catching-up and latecomer strategy: A case study of the Asian shipbuilding industry', Seoul Journal of Business 15(2), 25-57.

Sohn, S., Sung, N., Lee, M., Kim, D., Sung, K. and Kang, I. (2001), The Twentieth Century History of Korean Telecommunication (in Korean), Technical report, KISDI, Seoul.

Song, J., Almeida, P. and Wu, G. (2003), 'Learning-by-Hiring: When is mobility more likely to facilitate interfirm knowledge transfer?', Management Science 49(4), 351-365.

Song, S. (2008), 'From catch-up to innovation leader: Technological development of semiconductor in samsung (in korean)', Journal of the Korean History of Science Society 30(2), 517-544.

Suarez, F. F. and Lanzolla, G. (2007), 'The role of environmental dynamics in building a first mover advantage theory', Academy of Management Review 32(2), 377-392.

Teece, D. J. (1986), 'Profiting from technological innovation: Implications for integration, collaboration, licensing and public Policy', Research Policy 15(6), 285-305.

Winter, S. G. (1984), 'Schumpeterian competition in alternative technological regimes', Journal of Economic Behavior Organization 5(3-4), 287-320.

Zander, U. and Kogut, B. (1995), 'Knowledge and the speed of the transfer and imitation of organizational capabilities: An empirical test', Organization Science 6(1), 76-92.

Zhang, G., Wang, X., Duan, H. and Zheng, L. J. (2021), 'How do new entrants' pre-entry technological backgrounds impact their cross-industry innovation performances? A retrospective study of the mobile phone vendors', Technovation 100, 102176.

Zhu, F. and Iansiti, M. (2012), 'Entry into platform-based markets', Strategic Management Journal 33(1), 88-106. 
Figure 1: R\&D resource allocation and technological leadership change

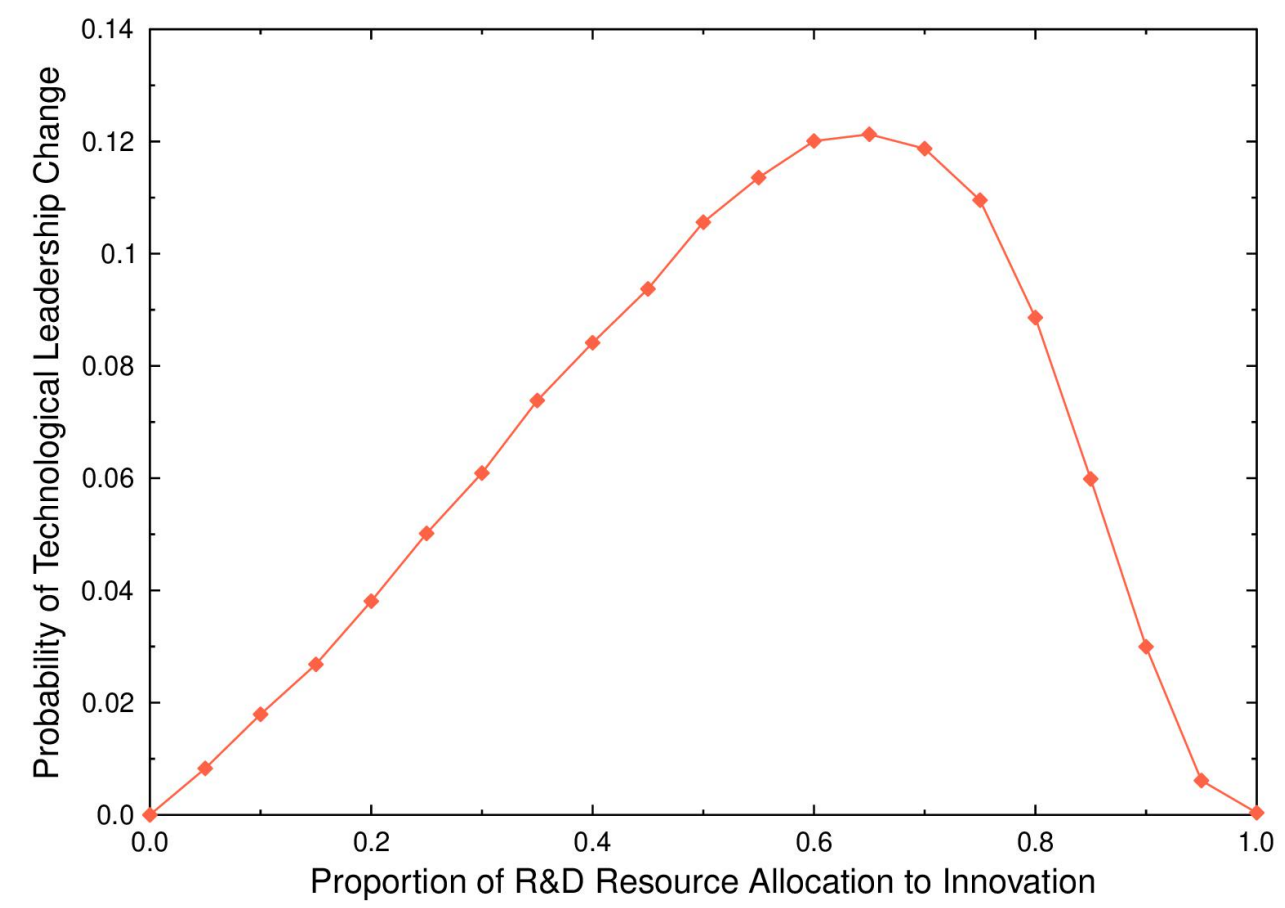

Note: The probability of technological leadership change reaches its peak when the latecomer balances R\&D resource allocation between innovation and imitation. The resulting values are averaged over 100,000 iterations of the simulation. The parameter values used are specified in Appendix A. 
Figure 2: Latecomers' technology levels, R\&D resource allocation, and technological leadership change

Panel A. Latecomers' relative technology levels and technological leadership change

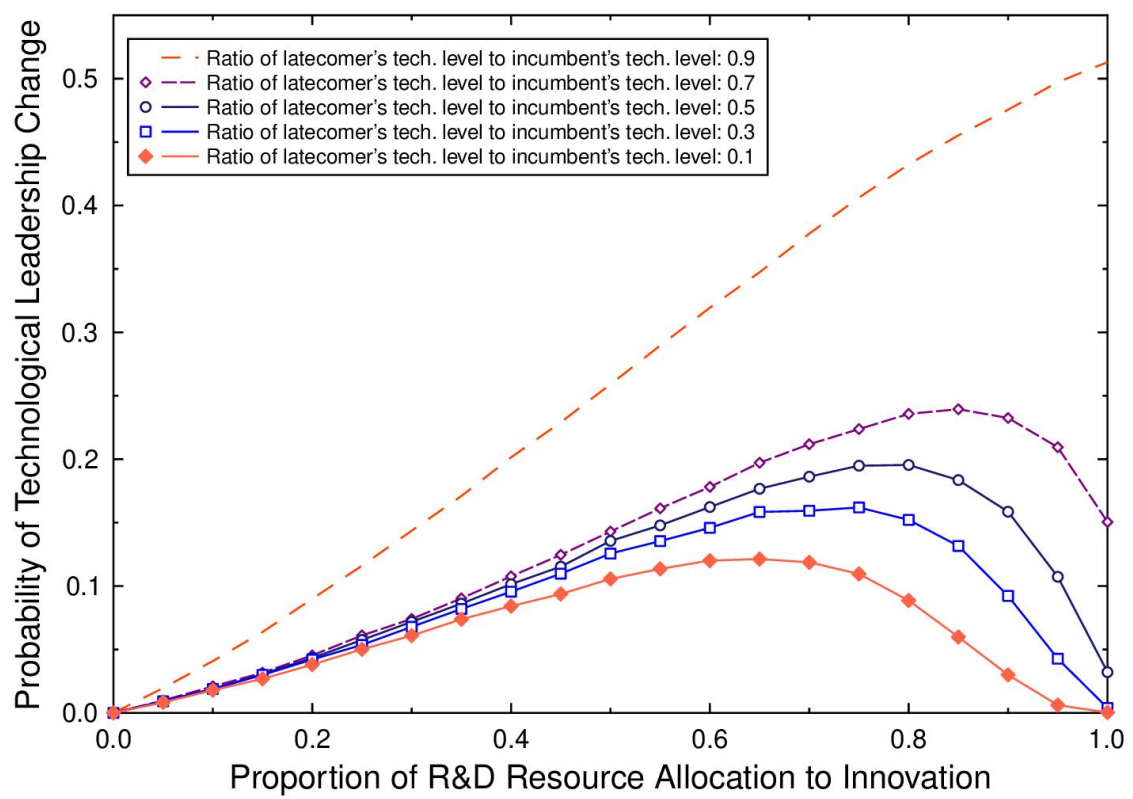

Panel B. Latecomers' relative technology levels and optimal allocation of resource to innovation

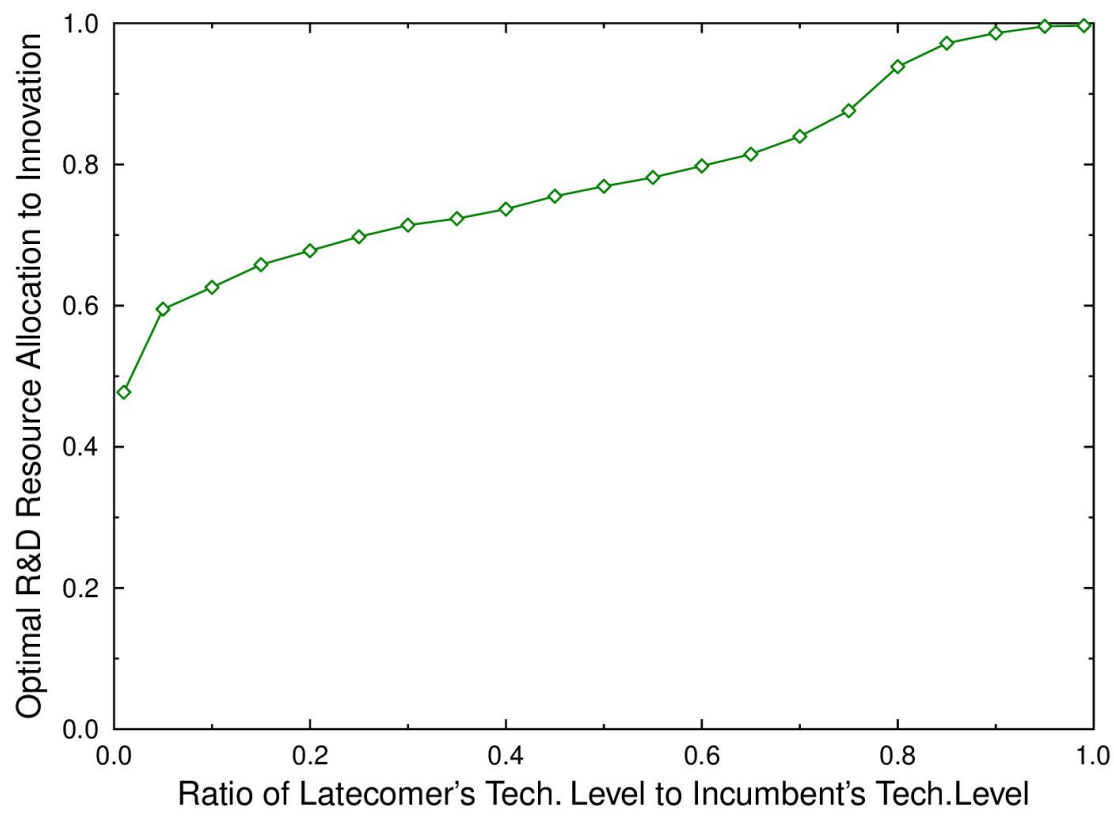

Note: As the latecomer's technology level relative to the incumbent's increases, the probability of leadership change increases. As the technological gap between the latecomer and the incumbent decreases, the latecomer should allocate more resources to innovation to increase the probability of leadership change. 
Figure 3: Appropriability, R\&D resource allocation, and technological leadership change

Panel A. Appropriability and technological leadership change

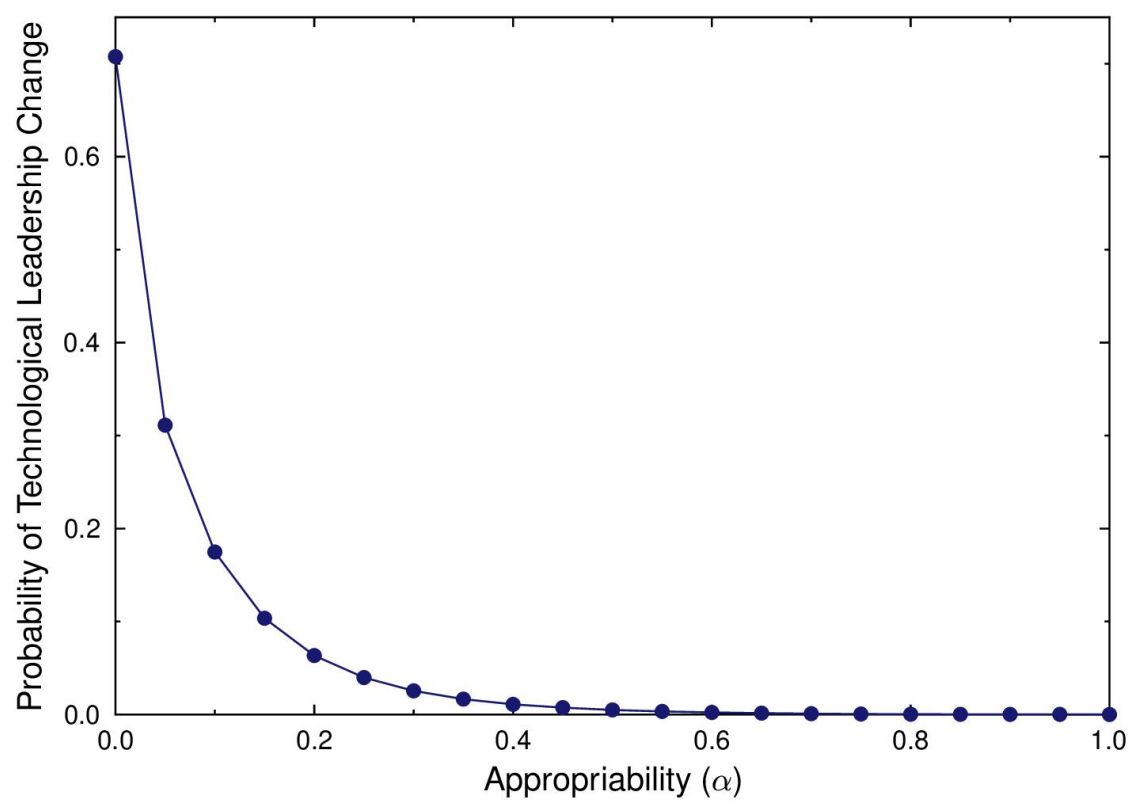

Panel B. Appropriability, resource allocation, and technological leadership change

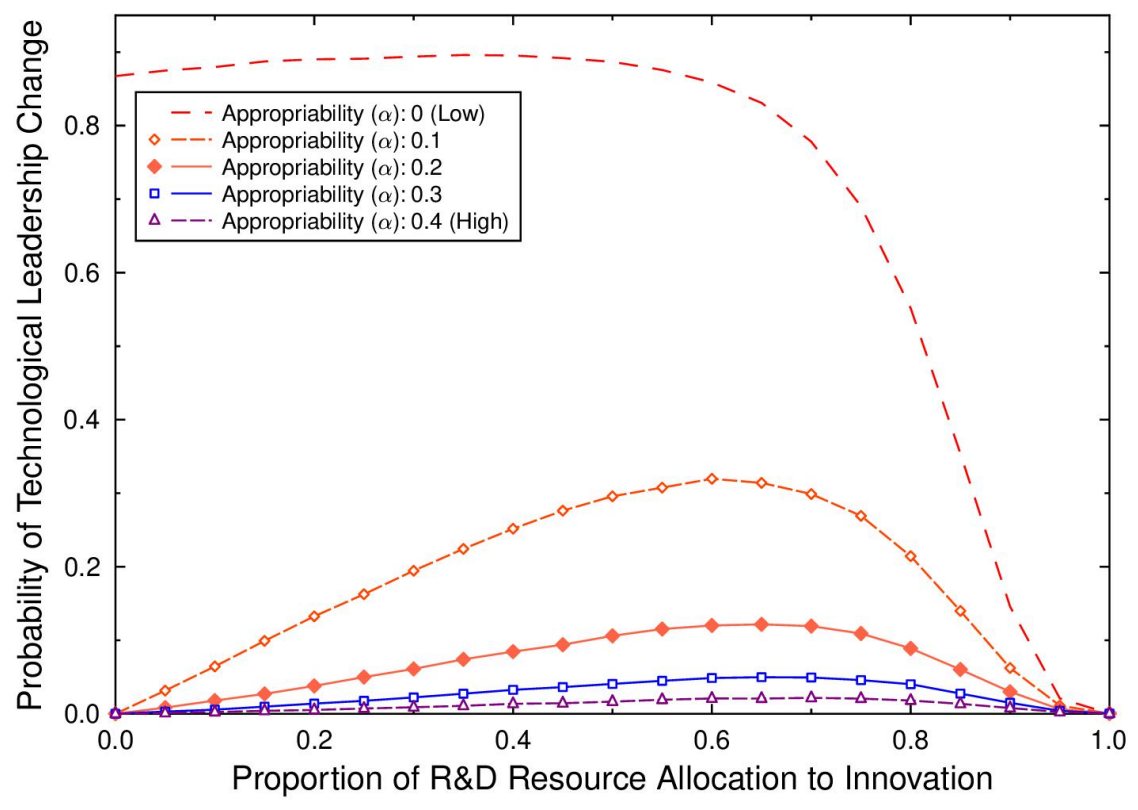




\section{Panel C. Appropriability and optimal resource allocation to innovation}

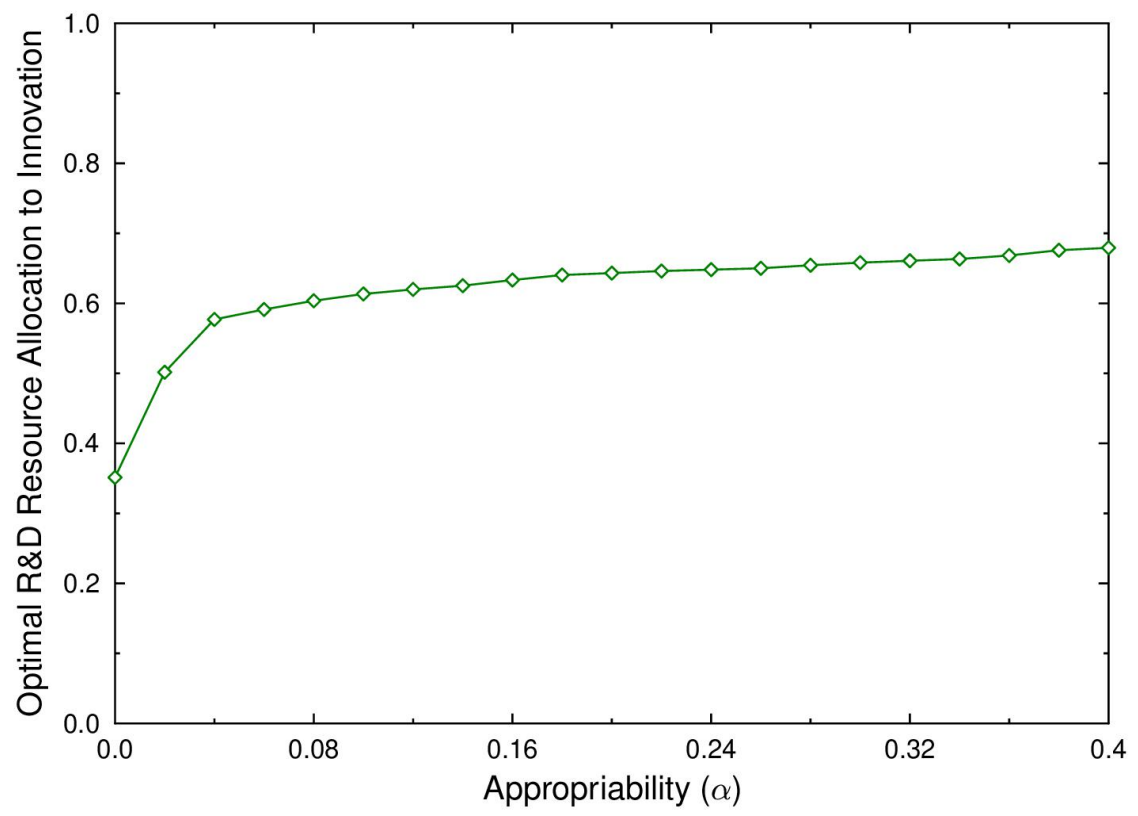

Note: Panel A shows that as the level of appropriability increases, the probability of technological leadership change increases. The probability of technological leadership change is the average of the leadership change probabilities when the amount of $R \& D$ resource allocated to innovation is between 0 and 1 . Panel $B$ shows that the inverted U-shaped relationship between the proportion of R\&D resource allocated to innovation and the probability of technological leadership change is sustained across the entire range of appropriability. Panel $\mathrm{C}$ shows that as the level of appropriability increases, the latecomer should allocate more resources to innovation to increase the probability of technological leadership change. 
Figure 4: Cumulativeness, $R \& D$ resource allocation, and technological leadership change

Panel A. Cumulativeness and technological leadership change

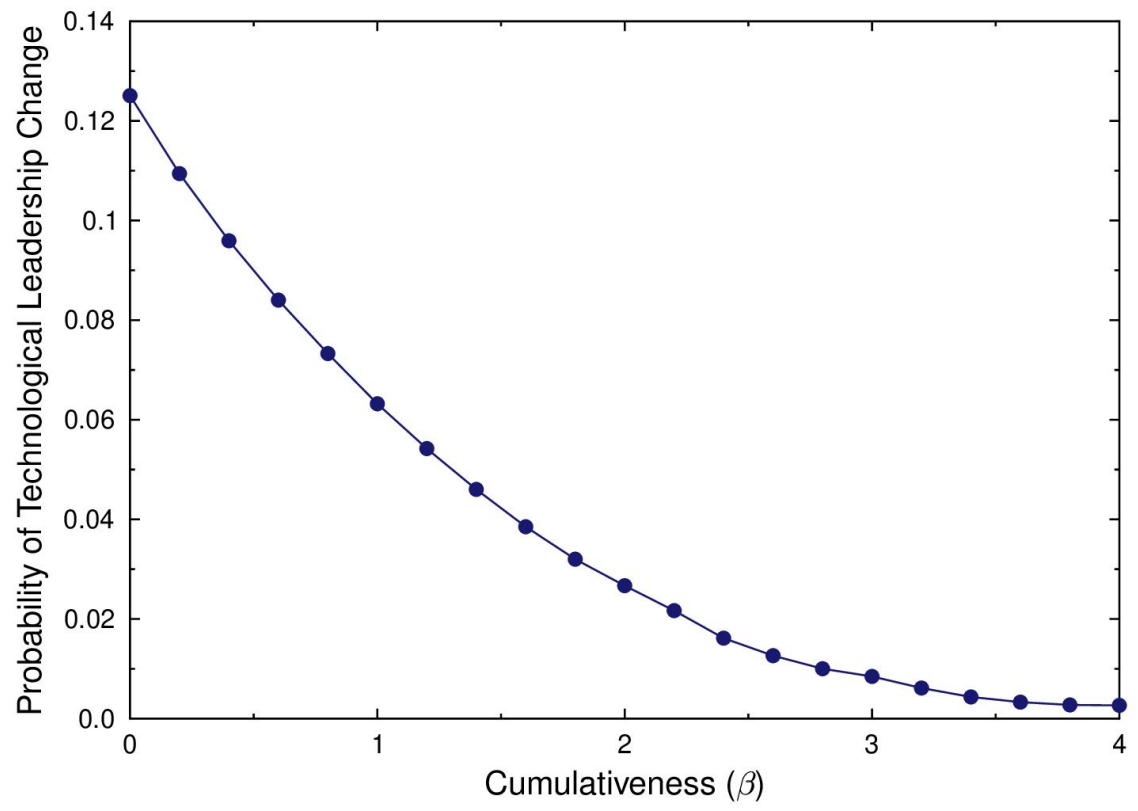

Panel B. Cumulativeness, R\&D resource allocation, and technological leadership change

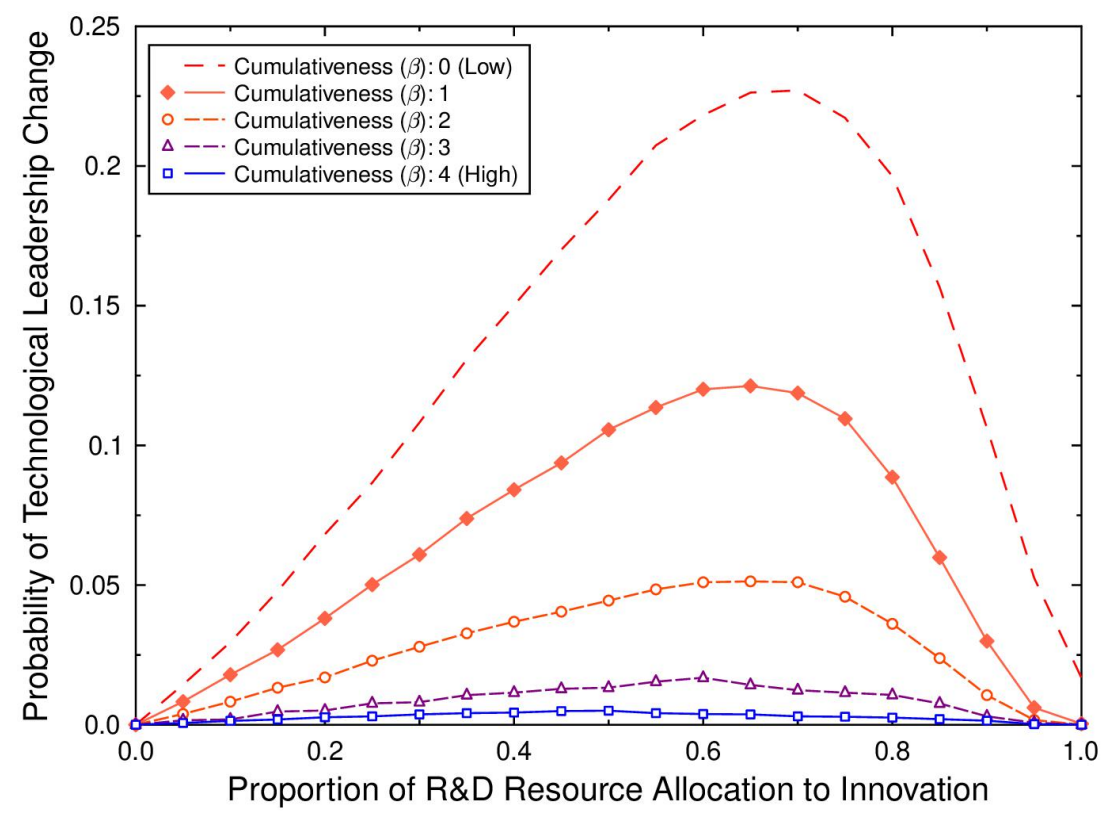




\section{Panel C. Cumulativeness and optimal resource allocation to innovation}

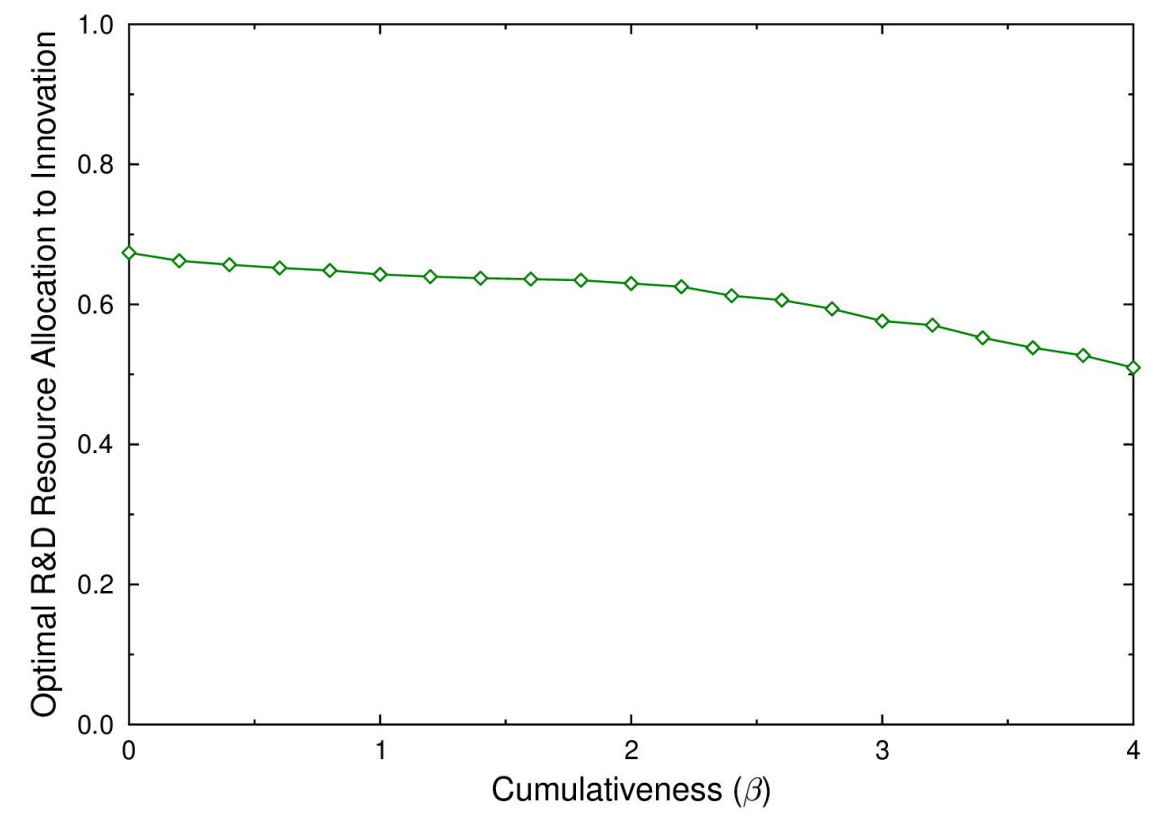

Note: Panel A shows that as the level of cumulativeness increases, the probability of technological leadership change decreases. The probability of technological leadership change is the average of the leadership change probabilities when the amount of $R \& D$ resource allocated to innovation is between 0 and 1 . Panel B shows that the inverted U-shaped relationship between the proportion of $\mathrm{R} \& \mathrm{D}$ resource allocated to innovation and the probability of technological leadership change is sustained across all levels of cumulativeness. Panel C shows that as the level of cumulativeness increases, the latecomer should allocate more resources to imitation to increase the probability of technological leadership change. 
Figure 5: Cycle time of technologies, R\&D resource allocation, and technological leadership change

Panel A. Cycle time of technologies and technological leadership change

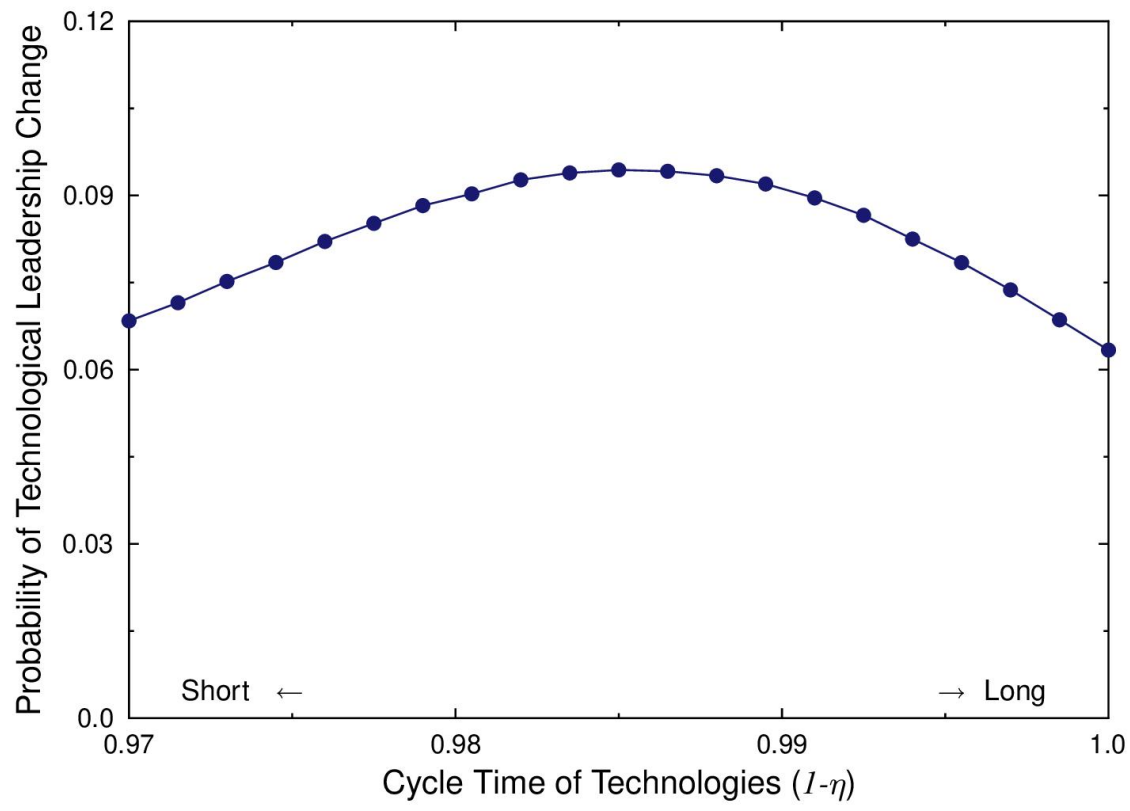

Panel B. Cycle time of technologies, $R \& D$ resource allocation, and technological leadership change

(CTT range: $0.97 \leq 1-\eta \leq 0.985$ )

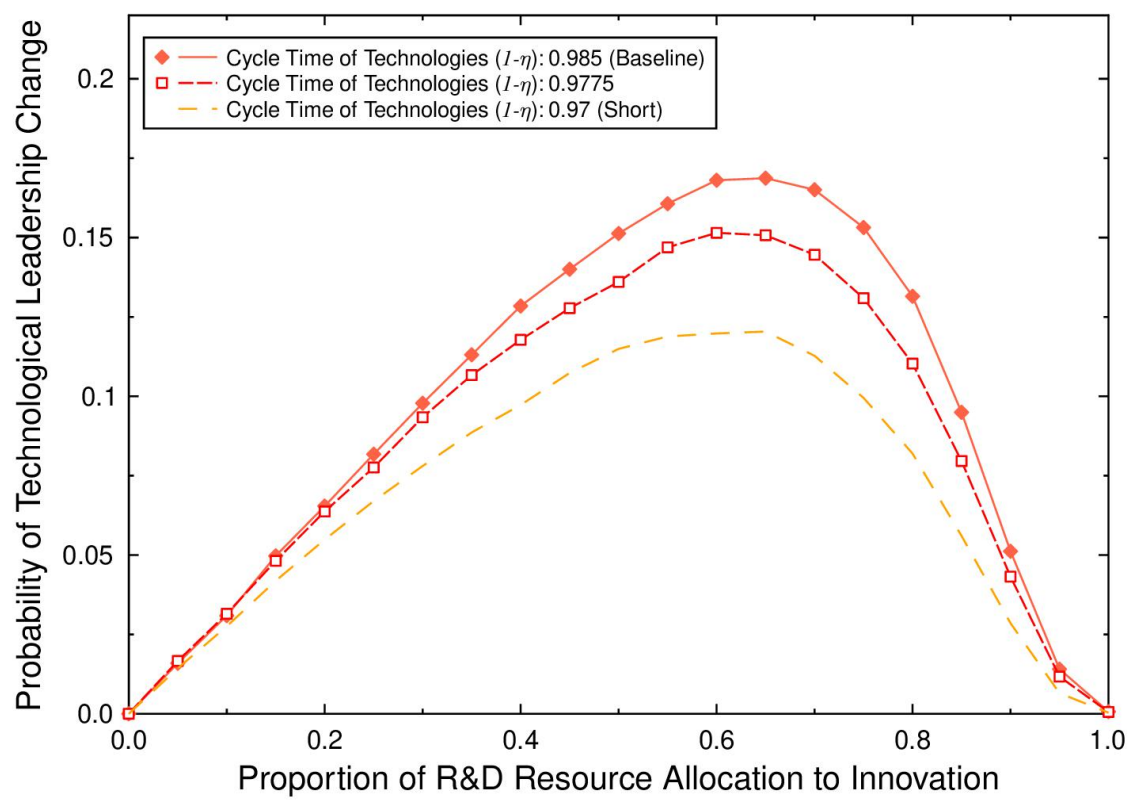


Panel C. Cycle time of technologies, R\&D resource allocation, and technological leadership change

(CTT range: $0.97 \leq 1-\eta \leq 0.985$ )

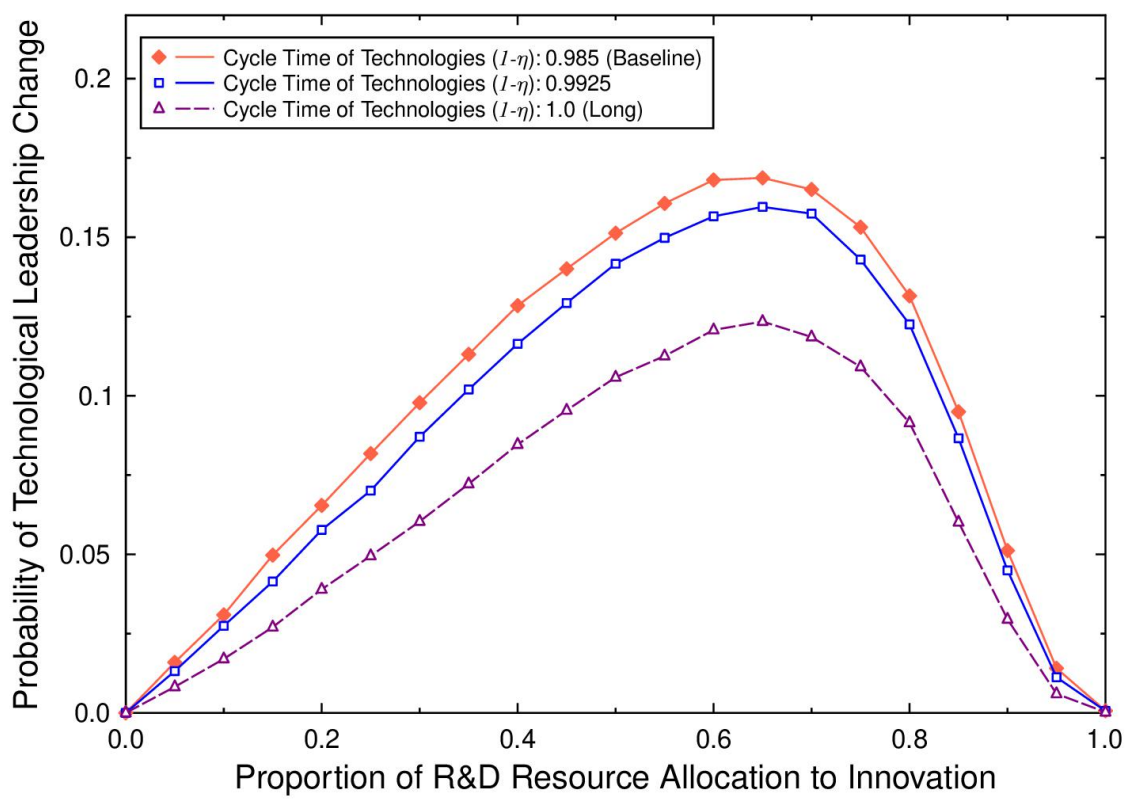

Panel D. Cycle time of technologies and optimal resource allocation to innovation

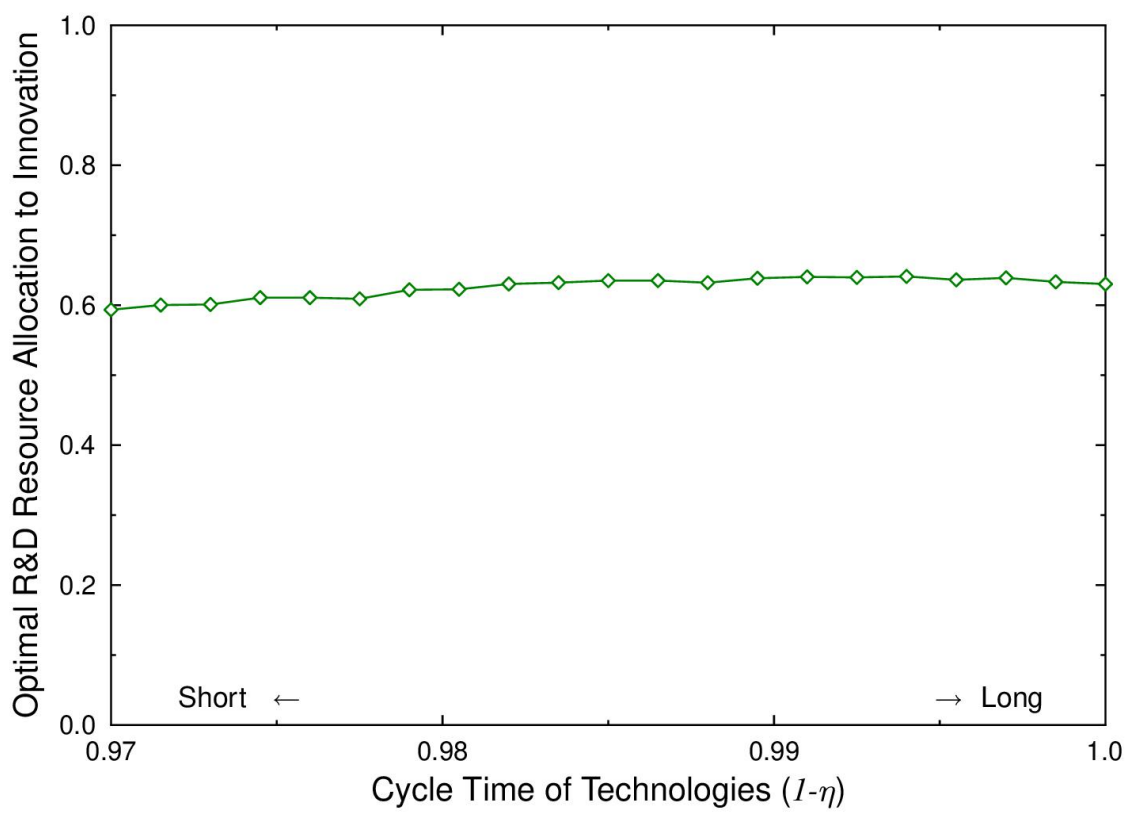

Note: Panel A shows an inverted U-shaped relationship between the CTT and the probability of technological leadership change. Panels B and C show that the inverted U-shaped relationship between the proportion of R\&D resource allocated to innovation and the probability of technological leadership change is sustained across all values of CTT. Panel D shows that the CTT does not significantly change the optimal proportion of R\&D resource allocated to innovation. 


\section{Figure 6: Cycle time of technologies and latecomers' relative technology level}

Panel A. Cycle time of technologies, latecomers' relative technology level, and technological leadership change

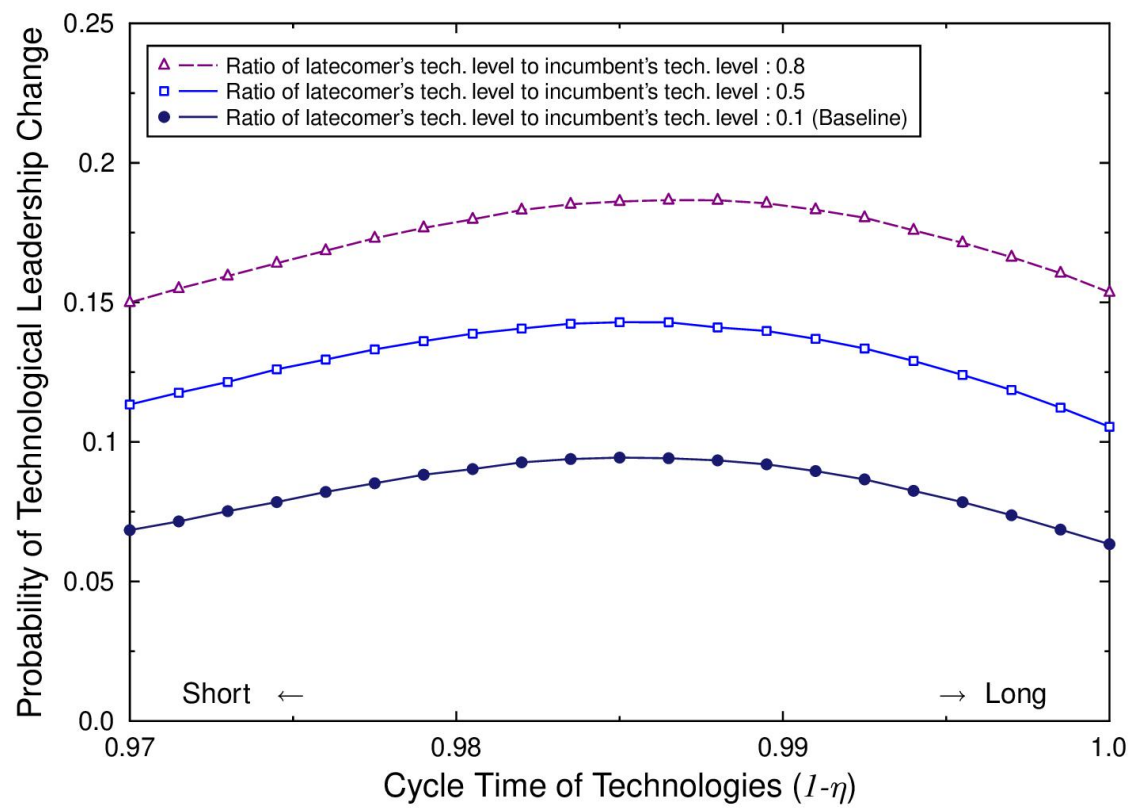

Panel B. Cycle time of technologies, latecomers' relative technology level, and latecomers' optimal resource allocation to innovation

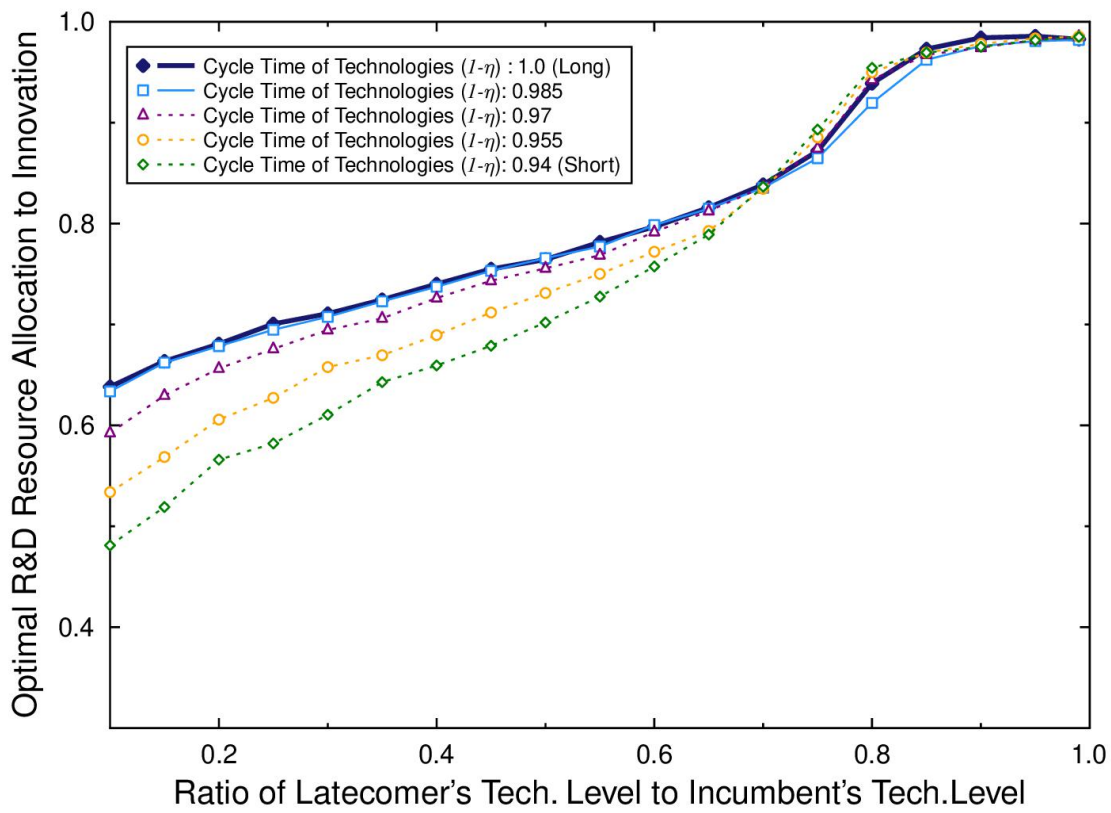

Note: Panel A shows that the CTT does not change the peak probability of technological leadership change with increasing latecomer's technology level relative to the incumbent's. However, Panel B shows that as the technological gap between the latecomer and the incumbent increases, the latecomer should allocate more resources to imitation to increase the probability of leadership change. 
Table 1: History of Samsung's DRAM development

\begin{tabular}{l|cccc}
\hline Products & Samsung's introduction & Incumbents' introduction & Gap & Line width \\
\hline $64 \mathrm{~K}$ & Nov, 1983 & May, 1978 & 5.5 years behind & $2.4 \mu \mathrm{m}$ \\
$256 \mathrm{~K}$ & Oct, 1984 & April, 1979 & 4.5 years behind & $1.1 \mu \mathrm{m}$ \\
$1 \mathrm{M}$ & Jul, 1986 & Jul, 1984 & 2 years behind & $0.7 \mu m$ \\
$4 \mathrm{M}$ & Feb, 1988 & Aug, 1987 & 6 months behind & $0.5 \mu m$ \\
$16 \mathrm{M}$ & Aug, 1990 & July, 1990 & 1 month behind & $0.4 \mu m$ \\
$64 \mathrm{M}$ & Sep, 1992 & - & Ahead & $0.35 \mu m$ \\
$256 \mathrm{M}$ & Aug, 1994 & - & Ahead & $0.25 \mu m$ \\
$1 \mathrm{G}$ & Oct, 1996 & - & Ahead & $0.18 \mu m$ \\
$4 \mathrm{G}$ & Feb, 2001 & - & Ahead & $0.13 \mu \mathrm{m}$ \\
\hline \hline
\end{tabular}

Note. Data in the table are from Samsung Homepage and Song (2008). 
Table 2: Probability of technological leadership change in various technological regimes

\begin{tabular}{|c|c|c|c|}
\hline \multicolumn{3}{|c|}{ Technological regime } & \multirow{2}{*}{$\begin{array}{c}\text { Probability of leadership change for latecomer } \\
\text { (latecomer's initial technology level is } \\
10 \% \text { of the incumbent's) }\end{array}$} \\
\hline Appropriability & Cumulativeness & $\begin{array}{l}\text { Cycle time of } \\
\text { technologies }\end{array}$ & \\
\hline High $(0.25)$ & High (1.2) & Long (1.0) & $3.24 \%$ \\
\hline High $(0.25)$ & High (1.2) & Moderate $(0.985)$ & $4.98 \%$ \\
\hline High $(0.25)$ & High (1.2) & Short $(0.97)$ & $3.02 \%$ \\
\hline High $(0.25)$ & Low $(0.8)$ & Long (1.0) & $4.73 \%$ \\
\hline High $(0.25)$ & Low $(0.8)$ & Moderate $(0.985)$ & $10.79 \%$ \\
\hline High $(0.25)$ & Low $(0.8)$ & Low $(0.2)$ & $9.64 \%$ \\
\hline Low $(0.15)$ & High (1.2) & Long (1.0) & $8.90 \%$ \\
\hline Low $(0.15)$ & High (1.2) & Moderate $(0.985)$ & $9.41 \%$ \\
\hline Low $(0.15)$ & High (1.2) & Low $(0.2)$ & $4.91 \%$ \\
\hline Low $(0.15)$ & Low $(0.8)$ & Long (1.0) & $11.68 \%$ \\
\hline Low $(0.15)$ & Low $(0.8)$ & Moderate $(0.985)$ & $17.48 \%$ \\
\hline Low $(0.15)$ & Low $(0.8)$ & Low $(0.2)$ & $13.84 \%$ \\
\hline
\end{tabular}

Note. The relationships between the technological regime variables and the probability of leadership change are sustained over all possible cases in the technological regime. 
Table 3: Optimal resource allocation to innovation under various technological regimes

\begin{tabular}{|c|c|c|c|c|c|}
\hline \multicolumn{3}{|c|}{ Technological regime } & \multicolumn{3}{|c|}{ Optimal resource allocation to innovation $\left(p^{*}\right)$} \\
\hline Appropriability & Cumulativeness & $\begin{array}{l}\text { Cycle time of } \\
\text { technologies }\end{array}$ & $\begin{array}{c}\text { Low } \\
\text { technology level } \\
\text { for latecomer } \\
\text { relative to } \\
\text { incumbent } \\
(0.1 \text { level })\end{array}$ & $\begin{array}{c}\text { Moderate } \\
\text { technology level } \\
\text { for latecomer } \\
\text { relative to } \\
\text { incumbent } \\
(0.5 \text { level })\end{array}$ & $\begin{array}{c}\text { High } \\
\text { technology level } \\
\text { for latecomer } \\
\text { relative to } \\
\text { incumbent } \\
(0.9 \text { level })\end{array}$ \\
\hline High (0.25) & High (1.2) & Long (1.0) & 0.63 & 0.76 & 0.96 \\
\hline High (0.25) & High (1.2) & Moderate $(0.985)$ & 0.62 & 0.74 & 0.94 \\
\hline High $(0.25)$ & High (1.2) & Short $(0.97)$ & 0.55 & 0.74 & 0.93 \\
\hline High $(0.25)$ & Low $(0.8)$ & Long (1.0) & 0.63 & 0.77 & 0.96 \\
\hline High (0.25) & Low $(0.8)$ & Moderate $(0.985)$ & 0.63 & 0.77 & 0.95 \\
\hline High $(0.25)$ & Low $(0.8)$ & Short $(0.97)$ & 0.60 & 0.75 & 0.94 \\
\hline Low $(0.15)$ & High (1.2) & Long (1.0) & 0.61 & 0.73 & 0.92 \\
\hline Low $(0.15)$ & High (1.2) & Moderate $(0.985)$ & 0.59 & 0.72 & 0.92 \\
\hline Low $(0.15)$ & High (1.2) & Short $(0.97)$ & 0.55 & 0.68 & 0.92 \\
\hline Low $(0.15)$ & Low $(0.8)$ & Long (1.0) & 0.62 & 0.74 & 0.92 \\
\hline Low $(0.15)$ & Low (0.8) & Moderate $(0.985)$ & 0.61 & 0.72 & 0.90 \\
\hline Low $(0.15)$ & Low (0.8) & Short (0.97) & 0.58 & 0.71 & 0.90 \\
\hline
\end{tabular}

Note. Table 3 shows that the "imitation to innovation" strategy is useful for technological leadership change in all possible cases. In each case, as the latecomer's technology level increases, the optimal amount of resources allocated to innovation gradually increases. 


\section{Appendix A: List of model parameters}

\begin{tabular}{|c|c|c|c|c|c|c|c|}
\hline \multirow[b]{2}{*}{ Parameters } & \multirow[b]{2}{*}{ Remarks } & \multicolumn{6}{|c|}{ Parameter values } \\
\hline & & Figure 1 & Figure 2 & Figure 3 & Figure 4 & Figure 5 & Figure 6 \\
\hline$T_{L 0}$ & Latecomer's initial technology level & 0.05 & $\begin{array}{l}\text { From } 0.01 \\
\text { to } 0.499\end{array}$ & 0.05 & 0.05 & 0.05 & $\begin{array}{l}\text { From } 0.01 \\
\text { to } 0.499\end{array}$ \\
\hline$T_{F 0}$ & Incumbent's initial technology level & 0.5 & 0.5 & 0.5 & 0.5 & 0.5 & 0.5 \\
\hline$K_{L 0}$ & Latecomer's initial capital stock & 50 & 50 & 50 & 50 & 50 & 50 \\
\hline$K_{F 0}$ & Incumbent's initial capital stock & 100 & 100 & 100 & 100 & 100 & 100 \\
\hline$R$ & Total consumer demand & 64 & 64 & 64 & 64 & 64 & 64 \\
\hline$a v c_{i}$ & Average variable cost per unit of capital & 0.146 & 0.146 & 0.146 & 0.146 & 0.146 & 0.146 \\
\hline$r_{i}$ & R\&D expenditure per unit of capital & 0.004 & 0.004 & 0.004 & 0.004 & 0.004 & 0.004 \\
\hline$\mu$ & Average of log-normal distribution ${ }^{\dagger}$ & -3 & -3 & -3 & -3 & -3 & -3 \\
\hline$\sigma$ & Standard deviation of log-normal distribution & 1 & 1 & 1 & 1 & 1 & 1 \\
\hline$\kappa$ & Success probability of imitation $R \& D$ & 0.3 & 0.3 & 0.3 & 0.3 & 0.3 & 0.3 \\
\hline$\gamma$ & Gamma & 0.2 & 0.2 & 0.2 & 0.2 & 0.2 & 0.2 \\
\hline$\alpha$ & Appropriability & 0.2 & 0.2 & $\begin{array}{l}\text { From } 0 \\
\text { to } 1\end{array}$ & 0.2 & 0.2 & 0.2 \\
\hline$\beta$ & Cumulativeness & 1.0 & 1.0 & 1.0 & $\begin{array}{l}\text { From } 0 \\
\text { to } 4\end{array}$ & 1.0 & 1.0 \\
\hline$\eta$ & $\begin{array}{l}\text { Technological knowledge depreciation } \\
(\text { Cycle time of technologies }=1-\eta)\end{array}$ & 0 & 0 & 0 & 0 & $\begin{array}{l}\text { From } 0 \\
\text { to } 0.03\end{array}$ & $\begin{array}{l}\text { From } 0 \\
\text { to } 0.06\end{array}$ \\
\hline
\end{tabular}

$\dagger$ Note: Values drawn from a log-normal distribution are always positive. 